\title{
Monitoring Approaches for Faecal Indicator Bacteria in Water: Visioning a Remote Real-Time Sensor for E. coli and Enterococci
}

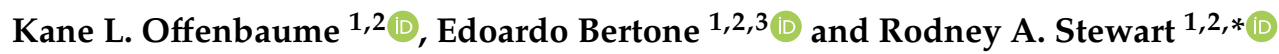 \\ 1 School of Engineering and Built Environment, Griffith University, Southport, QLD 4222, Australia; \\ kane.offenbaume@griffithuni.edu.au (K.L.O.); e.bertone@griffith.edu.au (E.B.) \\ 2 Cities Research Institute, Griffith University, Edmund Rice Drive, Southport, QLD 4222, Australia \\ 3 Australian Rivers Institute, Griffith University, 170 Kessels Road, Nathan, QLD 4111, Australia \\ * Correspondence: r.stewart@griffith.edu.au
}

Received: 17 August 2020; Accepted: 15 September 2020; Published: 16 September 2020

\begin{abstract}
A comprehensive review was conducted to assess the current state of monitoring approaches for primary faecal indicator bacteria (FIB) E. coli and enterococci. Approaches were identified and examined in relation to their accuracy, ability to provide continuous data and instantaneous detection results, cost, environmental awareness regarding necessary reagent release or other pollution sources, in situ monitoring capability, and portability. Findings showed that several methods are precise and sophisticated but cannot be performed in real-time or remotely. This is mainly due to their laboratory testing requirements, such as lengthy sample preparations, the requirement for expensive reagents, and fluorescent tags. This study determined that portable fluorescence sensing, combined with advanced modelling methods to compensate readings for environmental interferences and false positives, can lay the foundations for a hybrid FIB sensing approach, allowing remote field deployment of a fleet of networked FIB sensors that can collect high-frequency data in near real-time. Such sensors will support proactive responses to sudden harmful faecal contamination events. A method is proposed to enable the development of the visioned FIB monitoring tool.
\end{abstract}

Keywords: E. coli; enterococci; water quality monitoring; biosensors; portable fluorescence spectroscopy

\section{Introduction}

The faecal indicator bacteria (FIB) Escherichia coli (E. coli) and enterococci can cause gastrointestinal, respiratory, and/or skin infections [1-3]. E. coli and enterococci are the most typically monitored FIB and reducing the time to a result of monitoring operations is important for proactive management of waters [4].

E. coli are rod-shaped, Gram-negative facultative anaerobic bacilli found in the intestines of warm-blooded animals [5,6]. The presence of $E$. coli indicates the likely occurrence of pathogens linked to human faecal contamination and is a preferred indicator of faecal contamination in various water types [7-9]. Although many E. coli strains have low infectious doses, virulent strains (E. coli 0157:H7) can result in diarrheal infections, neonatal meningitis, septicaemia, and urinary tract infections $[6,10]$, and there have been increasing reports of certain E. coli strains blooming in environments without evidence of faecal contamination [11]. Similarly, the Enterococcus group consists of at least five species that live in the intestines of warm-blooded animals, and some strains can replicate in water containing kelp and plankton [12-14]. Enterococci are considered reliable FIB for both freshwater and estuarine recreational waters in tropical and subtropical environments and have been used successfully as indicators of health risk for marine environments and marine recreational waters [14-16]. Enterococci can tolerate drying environments and heterothermic habitats [13], and for monitoring most Australian 
environments Healthy Waterways [17] advocates using enterococci as a preferred indicator for the detection of faecal contamination in waterways due mostly to its reliability; however, Scott et al. [15] expresses there is some concern when environmental reservoirs of enterococci exist and natural regrowth of these organisms may influence detections in the environment.

The FIB presence in urbanised and parkland-area waterways is often influenced by old drainage infrastructure, illegal sewerage connections, groundwater leaching or associated land use, and the climate [7,18]. Moreover, high FIB is also linked to rainfall, urban runoff, sewage overflow, transport vectors, and floor sediment reintroduced into the water by recreational activities and by boat engines running too high in shallow waters $[17,19]$. Adverse health effects can be minimised by avoiding exposure to unsafe waters once contamination is detected; however, standard monitoring methods usually require a minimum of $24 \mathrm{~h}$ between sampling and results. This means infrequent, ad-hoc grab-sampling approaches are not suitable for short-term, early warnings of sudden contamination in large monitoring regions [8,20,21]. Consequently, predictive modelling is often used to forecast such contamination events [4]. Furthermore, imprecise water monitoring is a public health concern, and UNICEF's target product profile is calling for monitoring with more rapid detection of $E$. coli [22,23].

This review investigated FIB-related water monitoring preparation-type and measurement-type methods based on their detection effectiveness and usage in the industry. Preparation-type methods involved: membrane filtration assays, culture-based assays, polymerase chain reaction (PCR) and quantitative polymerase chain reaction (qPCR) assays, and deoxyribonucleic acid (DNA) probe assays. Measurement-type methods involved: absorption spectroscopy measurements and fluorescence measurements including fluorescence spectroscopy and flow cytometry. Typically, the fluorescence measurement is the final detection mechanism used by the majority of monitoring (of waters) applications described in this review paper. Other measurement-type methods included: biosensors, which house multiple detection mechanisms, $\beta$-D-glucuronidase (GUS) enzyme activity assays, adenosine triphosphate (ATP) bioluminescence assays, lateral flow assays, automated in situ biosensors using laboratory fluorescence measurements, or laboratory-in-vial (lab-in-vial) monitoring systems based on automated real-time defined substrate approaches within in situ and portable field kits. On the other hand, reagentless portable spectroscopy measurements were the most promising. These were investigated in greater detail to document how to improve their shortcomings, and if detection irregularities were removable based on previous investigations.

The overall goal of this review paper was to identify and describe the most currently used FIB monitoring approaches for water systems, discuss the pros and cons of each approach, and provide a roadmap to achieving an approach that satisfies all the requirements outlined in this chapter.

\section{Research Methods}

The flow chart in Figure 1 succinctly identifies the review process for this paper in accordance with the four-phase flow diagram from Moher et al. [24]. The collection procedure for the literature review included search, inclusion, and exclusion criteria. The primary search engine used was Google Scholar supplemented by the Research Gate database, Mendeley database, and Griffith University Library database. This review covered 288 studies, and the individual documents were initially selected using the following keyword search terms: faecal indicator bacteria, E. coli, enterococci, absorption spectroscopy, fluorescence spectroscopy, portable fluorimeter tools, real-time monitoring, water quality monitoring, recreational waters, environmental monitoring, culture-based methods, membrane filtration, enzyme substrates, ATP bioluminescence, DNA probes, PCR, qPCR, biosensors, automated real-time defined substrate approaches, automated lab-in-vial monitoring, and portable field kits. Only studies from 2009 to January 2020 were included; however, to introduce well-established monitoring techniques, or to add information on certain monitoring approaches for which limited literature was published in the last decade, we then included a small number of relevant, older references. 


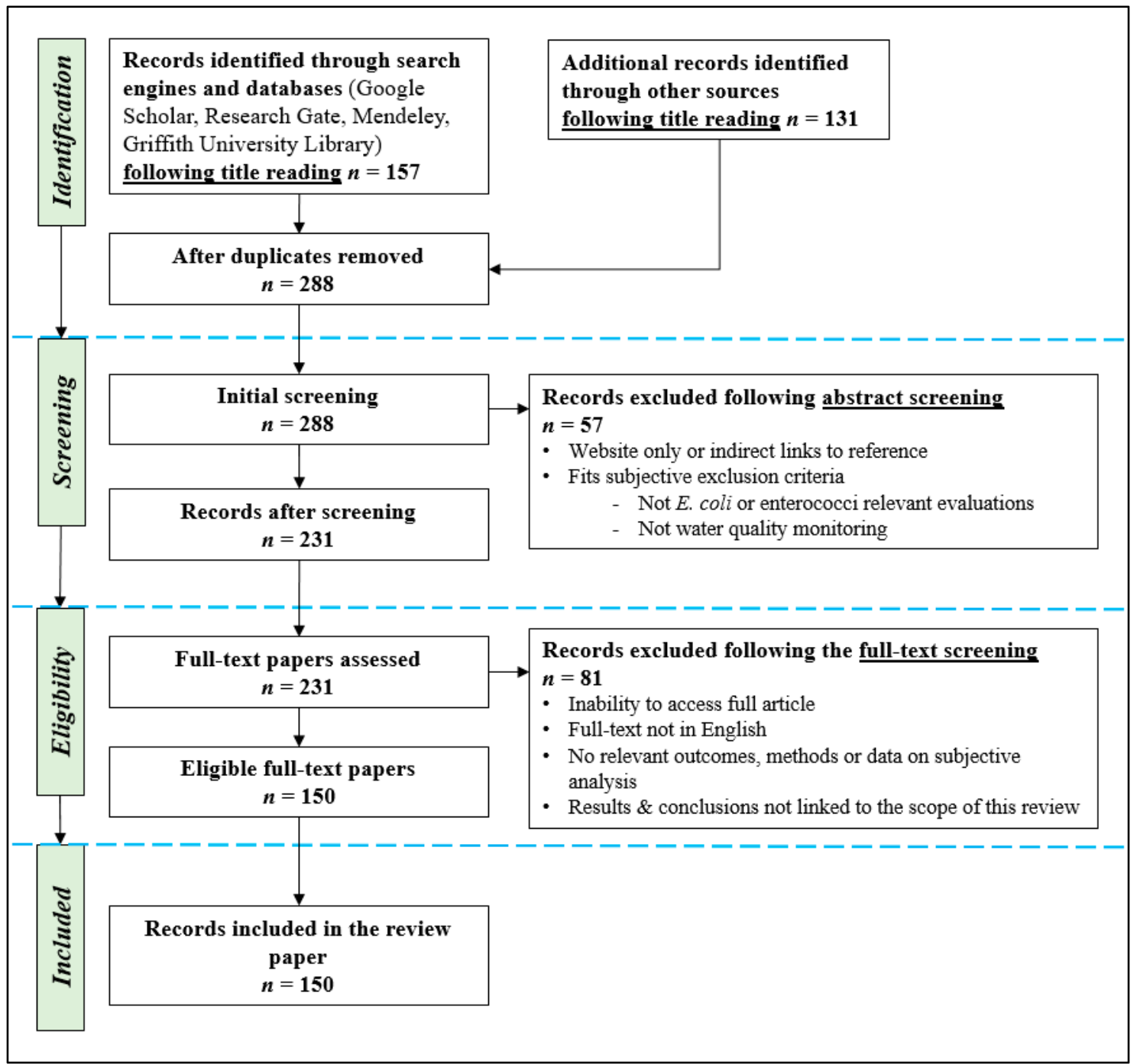

Figure 1. Literature review methodology, with screening through a three-stage filtering process: (1) title reading, (2) interpretation of the abstract, and (3) full-paper reading.

Irrelevant papers were subsequently removed from the original 288 papers using a three-stage filtering system to select papers by inclusion criteria: (1) title reading, (2) interpretation of the abstract, and (3) full-paper reading. Abstract screening was an important aspect of the initial screening process to synthesize the extant literature down to the citations that should be full-text screened and included in the review [25]. This filtering system resulted in 150 papers. This review critically investigated current research gaps in FIB detection tools and methods for the monitoring of E. coli and enterococci, including pros and cons, and provides future directions in these areas.

\section{Methodologies and Tools for Monitoring E. coli and Enterococci}

Methodologies and tools for monitoring E. coli or enterococci are identified and described in the following sections, along with their main features, pros, cons, and recent research advancements. The preparation-type method results typically involve preparation and require some form of filtration, extraction, or culturing before subsequent external measurements are taken; measurement-type methods primarily measure the prepared analytes. While some methods offer both preparation and measurement, these sections have been grouped according to whether the method spends the most time on preparation or measurement and the major outcomes of the technique; they have then been further subdivided. 


\subsection{Preparation-Type Methods}

\subsubsection{Membrane-Filtration Assays}

Membrane filtration techniques typically isolate discrete microbiological colonies of water samples and is used as a reference method for ISO standards [22]. This technique enumerates verifiable total coliforms (TC), E. coli, and enterococci [26]. The interested reader is directed to references [7,26-31], and Table A1 for the well-defined membrane filtration features.

Membrane filtration is not always effective for remedial monitoring due to its irregular specificity and sensitivity and its long time to result $[32,33]$. Membrane filtration can examine large water volumes in multiples; however, irregular results occur with high levels of turbidity due to clogging of membrane filters by any increased sediment levels [22]. This means that membrane filtration is very reliant on the membrane filter having the correct size (depending on site specificity). Clogged-material removal and result sensitivity also depend on the correct choice of membrane filter based on the organism being detected because membrane filtration is negatively influenced by low specificity [26-28,32]. Furthermore, the detection of slow-growing and viable but not culturable (VBNC) organisms relies heavily on organism-relative processes and increased detection time; in addition, detection bias in personnel occurs when items are detected by eye and when colonies present similarly in membranes or filters [7,26-29].

In general, membrane filtration often suffers from low sensitivity to low bacterial concentrations and repeated time-consuming processing under laboratory conditions. In addition, personnel are required for collection and processing because membrane filtration is not often portable or automated, typically due to its filtration processing, filter clogging, and long time to a result typically between 18 and $24 \mathrm{~h}[7,26-31,34]$.

\subsubsection{Culture-Based Assays}

The typical culture-based assay is a method of multiplying viral, bacterial, or protozoan pathogens by allowing them to reproduce in predetermined culture media under controlled conditions, and these are distinguished according to the culture medium broth cultures, agar plates, stab cultures, or solid plate cultures $[35,36]$. This is followed by the enumeration of any bacterial growth signals inspected through plate counting or biochemical or immunological techniques [36-40].

Generally, culture-based methods (CBM) are laborious assessments. While high-throughput developments enhance their processing, the processes remain lengthy because samples are collected and sent to laboratories for results to be provided within 18-24 h. This reduces effectiveness and contributes to reactive management when high-concentration events occur [22,39,41,42]. Unreliability is another issue, as CBM are often unable to provide reliable analyses of samples when the samples contain several different bacterial organisms or sediment levels such as in marine waters with high sediment levels, often returning false negatives and underestimations when the concentration of E. coli is low $[22,43,44]$. As a result, other detection techniques must be deployed to analyse complex samples $[39,45,46]$. This was confirmed by Guo et al. [32] when their CBM tests found that only $<3 \%$ of the total bacterial population in their water sample was culturable. Additionally, bacterial load is often underestimated because only viable organisms are detected, excluding VBNC [22,44].

In summary, CBM are widely used since they are simple and relatively inexpensive and can provide accurate results for water with low turbidity and detectable bacterial concentrations [22,36]. However, findings have shown that CBM cannot distinguish between faecal matter and host source [47], and that they can return low specificity and user bias when personnel miscalculate plate counts $[36,48]$. Moreover, the long wait time, the required laboratory equipment and trained personnel contribute to restricting its usefulness [22,36]. 


\subsubsection{Non-Real-Time and Real-Time Polymerase Chain Reaction Assays}

Polymerase chain reaction (PCR) assays are a common laboratory technique used in applications of molecular biological monitoring to identify and quantify selected DNA samples in water samples. This preparation-type test normally requires grab sampling followed by laboratory PCR processing where filtration is typically required, and DNA is extracted from the filters for quantification by whichever PCR method is applied [46,47,49-51]. Previous literature [22,46,50,51] and Table A1 provide more details about PCR features and procedures.

Many monitoring procedures combine PCR with fluorescently labelled probe hybridisation to create targeted amplification sequences, improving result accuracy and time to a result (in diagnostic laboratories) [37,46,52]. Lam et al. [52] investigated marine waters with a PCR and found their PCR method to be comparable to culture methods; their real-time PCR monitored the fluorescence emitted by hybridisation probes targeting the cyd gene and quantified as few as $25 \mathrm{E}$. coli colonies per $100 \mathrm{~mL}$ within four hours. Similarly, a drinking water survey by Frahm and Obst [53] used a PCR detection technique with TaqMan based on the exonuclease activity of Taq DNA polymerase to identify either E. coli or enterococci and obtained results identified by fluorescence within about five hours. Their increasing fluorescence signal was measured online following PCR. However, when the PCR detection technique with TaqMan and the fluorescence signal was used in natural waters, an approximate $18 \mathrm{~h}$ long incubation was required due to the increased complexity of natural waters; the accuracy nevertheless remained high [53].

Real-time PCR (also known as quantitative PCR (qPCR)) monitors the amplification of a targeted DNA molecule during instead of at the end of the PCR. qPCR is also performed in a laboratory, however it is more rapid and sensitive than regular PCR [22,54]. Quantitative PCR typically uses fluorescence identification through chemical dyes, and some results are provided in less than three hours. However, some qPCR assessments are affected by low specificity because it does not distinguish between living bacteria and dead or VBNC forms of bacteria (E. coli), as DNA remains whether a cell is dead or alive. This low specificity can be overcome by reverse transcriptase PCR. However, this type of PCR contains a highly toxic compound (propidium monoxide), making it inappropriate for widescale use, and it therefore cannot solve qPCR's issue with low specificity in most cases [30,36,45].

Modern PCR offers high accuracy, high throughput, multiple samples with simultaneous processing, semiautomated data collection and analysis, and fewer detection errors. Real-time PCR typically offers same-day results, with some approaches achieving results in about three hours. However, significant limitations of PCR approaches include the need for grab sampling; PCR also requires long periods of amplification, multiple thermal cycling steps, and expensive laboratory equipment in centralised testing facilities with skilled personnel $[7,46,47,53,55,56]$.

\subsubsection{DNA-Probe Assays}

A DNA probe is a stretch of single-stranded DNA that directly detects complementary nucleic acid sequences or target sequences in assays through hybridisation. Typical DNA-Probe assays use DNA probes as reagents often labelled with fluorescent tags to enable laboratory-based processing including a fluorescence-based analysis to detect faecal contamination in water [36,46,57].

A probe-based assay in the DNA-ELISA biosensor design proposed by Hashemi and Forouzandeh [58] uses a capture probe (biotin-labelled) to trap bacterial DNA against other bacteria under specific conditions. It also uses a detector probe (dig-labelled) to hybridise to the genome of the trapped bacteria. A special region of the 16S rRNA gene of E. coli ATCC 25922 was utilised. The assay was developed in sample solutions, and following a 30 min incubation period in darkness, the light absorbance of the solutions was measured at $405 \mathrm{~nm}$ for verification. The assay process was shown to detect results in about four hours. Multiple processes were required, and although the assays did not require amplification, the authors found that the detection-sensitivity limit was an improvement [58]. Another DNA-probe method relies on the fluorescence in situ hybridisation (FISH) process and is based on hybridisation with rRNA oligonucleotide probes. This assay detects 
and identifies microorganisms in mixed populations, often with qualitative or quantitative results for microbial cells [59]. Juhna et al. [60] used FISH to accurately detect E. coli strains (in a viable, metabolically active form) in biofilms on pipes of drinking water distribution systems through the 15-mer peptide nucleic acid (PNA) probe. Results were comparable to typical reference methods for E. coli. Similarly, Stender et al. [61] identified a chemiluminescent in situ hybridisation method based on PNA probes, which provides simultaneous detection and enumeration of culturable E. coli cells in $100 \mathrm{~mL}$ samples within one working day. However, the initial filtration and culture step of five hours inhibits rapid or continuous monitoring.

A DNA probe is a useful reagent-based tool for use in conjunction with other monitoring applications, such as fluorescence signaling. These preparation-type assays rely on nucleic acid techniques and are not typically influenced by environmental parameters. They provide sensitive, rapid, and quantitative analytical detection of organisms [36]. However, it is expensive to acquire the necessary equipment and DNA probes, along with the associated equipment for monitoring procedures, including safety measures. Nonetheless, DNA-probe technology could be incorporated into modern microfluidic devices to achieve reproducible and continuous results, both rapidly and accurately.

\subsection{Measurement-Type Methods}

\subsubsection{Absorption Spectroscopy Measurements}

The principle behind measurement using absorption spectroscopy is the spectral absorption of a sample at a defined wavelength. Algorithms convert the optical signal to a concentration of the parameter of interest. It is therefore described as a proxy technique rather than a direct-measurement technique [62]. Refer to references [63-65], and Table A1 for additional background information concerning absorption spectroscopy measurements and concentration conversion. Absorption spectroscopy offers reliable quantitative measurements because the absorbance is related to the intensity of light before and after it passes through the protein (molecular) solution, and the absorbance of solutes depends linearly on its concentration according to the Lambert-Beer law [63,65]. Optical sensors using absorption spectroscopy provide reagentless determinations for a range of parameters, but samples are typically preprocessed externally [62].

Kiefer et al. [64] successfully used UV/Vis/NIR absorption spectroscopy to define an accurate characterisation of the absorption spectra for E. coli cells in suspension (without reagents) and to quantify their data. Considering both sensitivity and accuracy, the authors found that the spectral range of about $420 \mathrm{~nm}$ provides high sensitivity for the quantitative determination of the number of cells. Park et al. [66] applied an assessment method that identified bacterial cells based on a UV-Vis spectroscopy analysis, for results within $3 \mathrm{~min}$. They required optical measurements using wavelengths of 230 and $670 \mathrm{~nm}$ for E. coli, Bacillus subtilis, and Staphylococcus epidermidis. However, their method was used for airborne bacteria (not water), and it could not be applied to samples with unknown bacteria or mixtures, and it therefore requires lengthy preparation to obtain clear bacterial samples [66].

Generally, absorption spectroscopy tools require the manual addition of samples for analyses that identify captured, tagged, or amplified compounds or specimens. Sensitivity concerns are usually addressed through laser- or molecular-modulation electrical components or semiconductor photodiodes $[62,67,68]$. Although absorption spectroscopy is useful for many applications and is widely used to determine known bacterial cell concentrations, it can be disturbed by a number of optical interferences and a risk of error. Sample preprocessing is typically required, and result times are typically long because the processing is laboratory-based and labour intensive; therefore, such methods are impractical in studies involving multiple sampling sites or frequent monitoring [68].

\subsubsection{Fluorescence Measurements}

Fluorescence is the result of released energy that occurs in fluorophores and generally follows a three-stage process: the excitation stage, the excited-state lifetime, and the fluorescence emission. 
In the excitation stage, fluorophores are excited by a high-energy light source, which produces the excited-state lifetime (the excited state exists for a finite time) and is followed by the fluorescence emission [69-71]. There are four elements involved in fluorescence detection systems: the excitation source, a fluorophore, wavelength filters to isolate emission photons from excitation photons, and a detector to register the emission photons and produce outputs [69].

Fluorescence measurement is inexpensive and reagentless and often requires little sample preparation; it is highly sensitive and non-invasive and allows the detection and characterisation of proteins, microorganisms, and inorganic, natural, and organic matter in water $[62,68,72,73]$. Fluorescence measurement instrumentation includes spectrofluorometers, microplate readers, fluorescence microscopes, fluorescence scanners (including microarray readers), and flow cytometers $[36,69]$.

In contrast with standard water-testing procedures, the fluorescence measurement enables fast or near-instantaneous results, and it can be used with or without reagents, thus reducing costs; however, currently, for E. coli and enterococci, results can be delayed by sample collection, preprocessing, and fluorescence measurement in laboratories [8,38,74]. Furthermore, most typical fluorescence sensors are bulky and expensive and are commonly affected by optical inferences; findings have shown that miniaturisation, filters, and compensation algorithms could overcome such limitations, but more experimentation is required $[62,72,73]$.

\section{Fluorescence Spectroscopy}

Fluorescence spectroscopy directly measures the specific fluorescence emission at a wavelength range produced by materials after excitation, and results are commonly expressed in fluorescence excitation-emission matrix (EEM) plots $[34,62,72,73,75]$ or through an absolute value if a specific excitation-emission pair is targeted based on known properties of the target parameter. The use of fluorescence spectroscopy as a final assessment tool to assess water quality in surface and ground waters has been reported and reviewed widely [34]. Fluorescence spectrometers are the final detection device or the final enumeration step for several methods mentioned in other sections of this review paper.

Cumberland et al. [34] made a successful attempt to record E. coli emission through reagentless portable fluorescence spectroscopy devices. They built on previous research that used peak-T fluorescence to detect contamination in water and found that low levels of coliform and E. coli bacteria $(<100$ per $100 \mathrm{~mL}$ ) could be detected within the peak-T2 range. Baker et al. [76] tested a more rigorous field assessment with the same portable fluorimeter and wavelengths, and results were promising when establishing a correlation between E. coli and a certain excitation-emission wavelength $(\lambda)$ pair, $\left(\lambda_{\mathrm{ex}}=280 ; \lambda_{\mathrm{em}}=350 \mathrm{~nm}\right)$. However, they found that at individual catchment scales, a more variable fluorescence intensity-E. coli relationship resulted, and optical interferences from $\mathrm{pH}$, thermal quenching and scattering of emitted fluorescence in turbid samples could affect the E. coli-fluorescence intensity relationship [76].

Fluorescence spectroscopy measurement systems can also use preprocessing assays for specific microbial detection. Findings have suggested that with improved calibration, these systems could provide viable results. For example, the TECTA system by Bramburger et al. [77] is comparable to standard CBMs in terms of accuracy but with overnight results. Other fluorescence spectrophotometers identify biotracked fluorescent proteins or chimeric biosensors, such as the fluorescent compound signal found in the green fluorescent protein through excitation and emission peaks. These peaks are tracked by spectrophotometers with light filters to defer optical interferences $[74,78,79]$.

\section{Flow Cytometry}

Flow cytometry is a fluorescence-based optical detection method that identifies individual cells including microorganisms within complex matrices, following cell staining with fluorescent tags [32,36]. Table A1 directs the reader to typical processing arrangements for flow cytometry, and in particular the references [36,80-82]. 
Modern flow cytometry relies on microflow devices to supplement conventional approaches; however, samples must be mixed and held before subsequent processes, which increases the result times [83]. Interestingly, automated analytical systems relying on flow cytometry have been widely deployed for FIB monitoring; Cyto-water [84] explained that their automatic flow cytometry-based system is capable of rapid detection of E. coli and other microorganisms, delivered on site in no more than two hours. Unfortunately, the device is not easy to set up, and regular maintenance is required; furthermore, labelling processes are required. On the other hand, the platform automatically concentrates a water sample and automatically labels each microorganism under investigation [84]. Tatari et al. [82] studied Aquascope technology with filter cytometry and FISH and found that it could detect $E$. coli or enterococci in sampling volumes of 1-500 mL. It accomplished a detection limit of $1 \mathrm{cell} / \mathrm{mL}$ and a response time of 20-45 $\mathrm{min}$. However, the company responsible for manufacturing, BioTrack, did not reply to enquiries. In addition, the authors identified that FISH has been integrated into a microfluidic device followed by flow cytometry to detect $E$. coli in pure cultures. However, they discovered that the main disadvantage of low concentrations in drinking water is that preconcentration (enrichment steps) might be needed [82], thus delaying time to a result and increasing processing. Additionally, the interpretation of results was a drawback for drinking water because it can be subjective, and proper standardisation of the counting process is essential [82], while for other types of water, low concentrations are not of great concern.

Flow cytometry is a type of automated fluorescence-microscopy system and a fast, accurate, and quantitative laboratory-based alternative to traditional FIB detection methods. However, significant limitations include the often time-consuming initial procedures, the need to stain cells and constituents with fluorescent tags and the expensive dyes and time-consuming sample preparation steps; additionally, because flow cytometry devices are typically expensive and inappropriate for use in frequent investigatory work in the field, they have limited onsite capabilities [32,68].

\subsubsection{Biosensors}

Biosensors exploit the biological reactions of proteins, cells, antibodies, enzymes, receptors, nucleic acids, and components. Biosensors detect microorganisms through a physiochemical transducer that is typically integrated into an electrical interface, which converts substance concentrations into electrical signals. Biosensors that require sample preprocessing, concentration, or enrichment procedures are common, and results are typically comparable to conventional FIB detection methods and high-accuracy tools $[3,29,59,85,86]$.

Biosensors for E. coli or enterococci detection are grouped according to the type of substrate or physiochemical signal [3,87]; Table A1 provides more information about the categories of biosensors. In general, biosensors offer accurate and rapid results, but many remain sensitive to coinhabiting microorganisms and interferences, and some modern biosensors are better evaluated with specific environmental samples, to reduce problems related to selectivity and sensitivity [87]. Additionally, some surface-based and weight-detection systems and vibrational tools are sensitive to changes in molecular mass or sample-analyte mass. Many biosensors require preprocessing with an intermediary or manual step, including filtration and culturing, and detections are not always possible in remote locations, as many require personnel for physical measurement $[29,30,59,87]$.

The biosensors described in the following subsections detect bacteria using particular substrates and transduction platforms, and some biosensors involve miniaturising analytical techniques and automatic laboratory-in-vial systems (lab-in-vial). Each of the following subsections introduces a type of biosensor and provides examples of its usefulness in applications and areas of improvement.

\section{Electrochemical Biosensors}

Electrochemical biosensors are self-contained integrated devices with electrochemical transduction elements that perform quantitative or semiquantitative analyses based on chemical reactions and bioreactions [3]. 
Many of this type of biosensor provide same-day and accurate results. For example, a custom-designed biosensing platform reviewed by Kumar et al. [88] uses AuNP-coated biochips, cyclic voltammetry and an amperometry transduction platform. It is found to offer a detection limit of $50 \mathrm{CFU} / \mathrm{mL}$ in eight minutes (in laboratory); its cost is high, but it is reusable. On the other hand, a label-free detection platform reviewed by Kumar et al. [88] uses a dielectrophoretic microfluidic chip substrate and electrochemical impedance transduction platform. It provides a detection limit of $300 \mathrm{CFU} / \mathrm{mL}$ for $E$. coli after $<1 \mathrm{~min}$ analysis. This biosensor is meant for drinking water assessments, and it is reusable but expensive. However, a major limitation associated with label-free detection platforms is the lack of specificity. Therefore, the authors suggested implementing specific tagging of the targeted organisms prior to testing these biosensor transduction platforms, but this would then increase the analysis time [88]. The biosensor developed by Thakur et al. [89] incorporates a thermally reduced graphene-oxide-based field-effect transistor passivated with an ultrathin layer of $\mathrm{Al}_{2} \mathrm{O}_{3}$ for label-free and low-cost results. This biosensor takes high-sensitivity measurements of single cells of E. coli in $1 \mu \mathrm{L}$ of water within $50 \mathrm{~s}$; although the biosensor was single use, the authors indicated that regeneration was possible through the development and use of a suitable regeneration buffer [89].

\section{Paper-Based Biosensors}

Paper-based biosensors use paper substrates to detect $E$. coli or other biological contaminants through their novel designs and material platforms. Findings have shown that paper-based biosensors are promising tools with reliable detection and speed.

Several paper-based biosensors were documented by Kumar et al. [88] in their review of point-of-care strategies for the detection of pathogens through typical surface-based biosensors. They identified a promising paper-based biosensor that uses filter paper as its substrate and a fluorescence-transduction platform to detect $E$. coli concentrations with a detection limit of $10 \mathrm{CFU} / \mathrm{mL}$; although it was single use with a moderate cost, it allowed same-day results in $5.5 \mathrm{~h}$. Another device is the DipTest litmus test for E. coli detection in water. It was developed by Gunda et al. [90] as a transduction-platform biosensor that uses a litmus paper substrate and colorimetry DipTest; they found that in aqueous solutions and with a 2 min dip time, the test could detect as low as $200 \mathrm{CFU} / \mathrm{mL}$ of $E$. coli in $180 \pm 20 \mathrm{~min}$. For higher concentrations and with a $2 \mathrm{~min}$ dip time, the test detected $2 \times 10^{5} \mathrm{CFU} / \mathrm{mL}$ in $75 \pm 12 \mathrm{~min}$. Additionally, with a $90 \mathrm{~min}$ dip time, the test detected as low as $200 \mathrm{CFU} / \mathrm{mL}$ in $54 \pm 8 \mathrm{~min}$. For higher concentrations and with a $90 \mathrm{~min}$ dip time, the test detected $2 \times 10^{5} \mathrm{CFU} / \mathrm{mL}$ within $28 \pm 5 \mathrm{~min}$. This biosensor was tested on different water samples and bacteria levels, with the paper strip dipped in water samples contaminated with E. coli. The concentrated E. coli on the paper strip reacted to produce a pink colour and indicate its presence with a low detection limit. This is a low-cost device with same-day results but is single use only [90]. A promising method using a smartphone (with gyroscope installed) to detect $E$. coli in field water samples (through paper microfluidics) was demonstrated by Park and Yoon [91] when their three-channel paper chip provided low- and high-concentration detection. Field samples were introduced to the paper chip (through either dipping or pipetting), and antigens from E. coli travelled through the paper fibres by capillary action, while other items in the water (dust, soil, and algae particles) were filtered out. The sample volumes tested were $7 \mu \mathrm{L}$, and a smartphone camera with an app determined the qualitative results for E. coli (specific angle-view detection onto the paper); the assay time of the preloaded paper chips was about $90 \mathrm{~s}$. The system was not described as reusable but required only their paper chip with preloaded antibody-conjugated beads, a smartphone with a built-in gyro-sensor and the installed software application [91]. However, they identified, for the detection of high bacterial concentrations the field water samples had been previously incubated at $37^{\circ} \mathrm{C}$ for up to $20 \mathrm{~h}$. Therefore, it was unclear whether the $90 \mathrm{~s}$ assay time began after preprocessing. 


\section{Lateral Flow Assay Biosensors}

Lateral flow assays (LFAs) are point-of-use tools and a type of strip biosensor useful for diagnostic purposes by making detections based on the fundamentals of chromatography in simplified sensor formats [92]. The typical prefabricated strips of the carrier material used by LFAs are activated by applying fluid samples. They characteristically utilise complex formations between a detector reagent, bound to coloured particles that comigrate in the sample stream, and a capture reagent, bound to the membrane at the position of the test line [93,94].

Lateral flow assays are attractive detection tools due to their portability, rapidity, moderate cost, and simple use. Some LFAs offer qualitative analyses or quantitative data by recording colorimetric responses with strip readers through either charge-coupled device (CCD) systems or a photomultiplier tube [92]. Lateral flow assays detect emergent strains, bacterial indicators, pathogens, or drugs in water within complex sample constituents [93]. The lateral flow immunoassay device by Bubert et al. [95] could qualitatively confirm the presence of E. coli 0157:H7 isolates in less than 30 min after an overnight enrichment of the water sample in ReadyCult culture media. Improving upon this, Kumar et al. [88] identified an LFA device that uses a colorimetry-transduction platform with a substrate of sol-gel-derived ink-coated silica test strips. It has a detection limit for E. coli 0157:H7 of $5 \mathrm{CFU} / \mathrm{mL}$ and analysis time of $30 \mathrm{~min}$. The authors identified that with the inclusion of a bacterial-culturing step allowed detection of $8 \mathrm{CFU} / 100 \mathrm{~mL}$ E. coli cells in $8 \mathrm{~h}$. This device is promising because it is reusable and has a moderate cost, but test samples likely required preprocessing [88].

Nucleic acid lateral flow immunoassays detect the genetic markers of organisms, and in a typical layout, the analyte is an amplified (using PCR) double-stranded nucleic acid sequence specific to the organism. The analyte uses primers with two different tags. The organism is recognised through a binding to its tag-specific antibody; or recognition is similarly reliant on the hybridisation of target DNA combined with a specific DNA probe [92-94]. Kumar et al. [88] reviewed a promising high-cost but reusable LFA device for E. coli analysis in water. It uses a colorimetry-transduction platform, with Flinders Technology Associates (FTA) cards for extraction and glass fibres for amplification substrates of nucleic acid. A PVC material promotes transportation of the sample from extraction to amplification and to lateral flow zones for the detection of E. coli concentrations, with a detection limit of 10-100 CFU/mL but the analysis time was not clearly identified [88].

Most LFAs offer simplified sensor formats for rapid onsite detection, are not heavily influenced by environmental parameters, return high sensitivity and specificity, and, overall, provide simple and cheap point-of-care tests for analytes [92,93]. However, improvements must be made to handle matrix obstruction [88]. Moreover, most LFAs require a lengthy preprocessing of test samples, sample liquids must pass along the strip of detector material and through the intended zones correctly to avoid inaccuracy, and the majority are not reusable. Furthermore, the analysis time of LFAs is dependent on the nature of the sample, and they require improvements in signal amplification, sample volume accuracy and the sensitivity limit [88].

\section{Micro-Raman Spectroscopy Biosensors}

The biosensors that use infrared and Raman spectroscopy provide vibrational fingerprints based on the chemical composition of bacteria for the discrimination of these bacteria in water samples [3], allowing accurate monitoring with high reproducibility.

A promising method by Liao et al. [96] provides fast and accurate detection of E. coli K12 in water droplets using electric field effects and micro-Raman spectroscopy without the need for signal amplification. The method under development by Liao et al. [96] uses micro-Raman spectroscopy interfaced with a microfluidic detection platform to offer in situ detection and characterisation. Following movement of the sample across the detection surface, the micro-Raman spectroscopy and the specific antibodies use alternating-current electrokinetic effects to capture E. coli species. This is a simple, sensitive and label-free method and detection is successful at concentrations as low as $10^{2}$ bacteria/mL from $50 \mu \mathrm{L}$ sample droplets and after captured microorganisms are examined 
following processing results are available within a few minutes. However, testing requires collection personnel, the processes are non-automated and non-continuous, and the authors did not identify whether the microelectrode chips were reusable. Additionally, Liao et al. [96] identified irregular results under laboratory conditions and suggested improvements, including adding a water immersion lens to eliminate washing and drying steps, developing a flow-through microfluidic system for online sample monitoring, using monoclonal antibodies to improve selectivity and using an immobilisation method to increase the antibody surface density. Only a small number of examples were found to detect $E$. coli, and these suffered irregularities. Along with the necessary preprocessing time, these irregularities limit the current effectiveness of these biosensor types.

\subsubsection{Adenosine Triphosphate Bioluminescence Assays and Biosensors}

Adenosine triphosphate (ATP) is the primary energy carrier in all living cells; its concentration in microorganisms varies depending on species and strain, metabolic activity, and environmental factors [87]. Bacterial ATP can therefore be an excellent indicator of microbial contamination [36]. Fundamentally, all common ATP-bioluminescence assays follow the same preprocessing procedures. Bacterial indicators are isolated (if present) when water samples with bacteria are filtered through membranes, which act as filters or membrane filters. They are then sprayed with ATP release reagents (or developed within the membranes or filters) for subsequent ATP extraction from the cells through cell lysis. This is done because when cells are assayed with the substrate luciferin and oxidised in the presence of the enzyme luciferase, this produces energy released as bioluminescent light $[20,41]$. This bioluminescence is collated by cameras or other image collection tools for quantifiable results [20].

Biosensors using ATP bioluminescence and bioluminescence detection are useful tools for the monitoring of water quality. When performing biorecognition through substrate and ATP-bioluminescence transduction platforms, they translate the biological or chemical signal into a physical quantity [85]. An example by Chollet and Ribault [20] is the Milliflex Rapid Microbiology Detection and Enumeration System, which is an ATP-bioluminescence protocol for the laboratory testing of environmental waters. In their study, first, samples were filtered; second, the sample was incubated onto media; third, the membrane was separated from media and dried; and fourth, the ATP release and bioluminescence reagents were autosprayed onto the membrane filter. Finally, the membrane filter was placed onto their detection tower for $\mathrm{CCD}$ camera light detection. Results viewed using their computer software determined E. coli within six hours. However, although the results were accurate and same-day, they were not rapid, and the samples and membrane filters were required to be manually placed. The process also required grab sampling as this biosensor is not portable or used in situ [20].

Faster results were found when ATP assays, combined with immunomagnetic separation (IMS), successfully detected E. coli and enterococci [41]. This was expressed by Lee and Deininger [97] when their tube-based IMS, combined with an ATP assay, determined E. coli at 10-20 CFU/100 mL in less than $1 \mathrm{~h}$ without an enrichment step. However, the laboratory processing was labour intensive, since after grab sampling and transportation, the beach samples were filtered twice: prefiltered with a filter with pore size $20 \mu \mathrm{m}$ to remove large particles and filtered again through a filter with pore size $0.45 \mu \mathrm{m}$. Samples containing E. coli were then resuspended and mixed with beads coated with E. coli antibodies. After IMS processing, E. coli was quantified by ATP bioluminescence [97]. However, the antibodies on the beads likely cross-reacted with other bacteria, meaning the estimated number might be slightly higher than that for E. coli alone. This prompted the authors to suggest future research focused on utilising a mixture of antibodies to detect multiple coliform groups and to improve bead accuracy and procedure [97]. Zimmer-Faust et al. [98] improved upon Lee and Deininger [97] when they developed a covalently-linked IMS-ATP method to enumerate enterococci in estuarine coastal waters. It is comparable with standard methods; however, Zimmer-Faust et al. [98] determined that further research was needed to develop more target-specific antibodies and to further optimise their preabsorption to reduce cross-reactivity. 
An immiscible filtration assisted by surface tension (IFAST) and the ATP-bioluminescence assay biosensor method was displayed by Ngamsom et al. [31] to provide fast determinations of samples spiked with E. coli 0157:H7 from small sample volumes. Results were obtained within $20 \mathrm{~min}$, and with a detection limit of $6 \mathrm{CFU} / \mathrm{mL}$. This inexpensive and portable $E$. coli detection method based on an IFAST chip fabricated from PDMS and an ATP-bioluminescence assay showed great potential in its development phase and was presented at an international conference [31]. The authors' microfluidic method was proposed to be portable and semiautomated, the IFAST chip enables rapid isolation with high specificity, and the ATP-bioluminescence assay gives high sensitivity. However, the method was tested in a laboratory and required multiple processing steps before ATP assay detection. Finally, the PDMS chip was placed in a detection box containing a photomultiplier tube connected to a digital meter [31]. Thus, the multiple steps and manual processing required limit this biosensor's effectiveness, and its reusability was not clearly identified.

Findings have shown that bacterial ATP is an excellent microbial contamination indicator and that bioluminescence is a powerful tool when coupled with photon counting and CCD camera devices [20]. Several methods incorporate this measurement method for reliable results. However, ATP-bioluminescence assays typically involve expensive enzymes [87]. Quenching of emitted light through bioluminescence commonly occurs and disturbs measurements. Furthermore, there is inconsistency between the measured signal and the number and activity of organisms. It is also not possible to always distinguish between viable and non-viable cells. These assays are not as sensitive as CBMs when detecting E. coli and enterococci and typically require grab sampling followed by multiple processing, often under laboratory conditions [20,41], all limiting efficiency.

\subsubsection{Enzyme Activity Assays and Biosensors}

Enzyme activity assays provide quantitative or qualitative detection. This type of detection uses enzyme chemistry and fluorescence substrates. The results are typically gathered through external measurement devices but can be viewed by eye in some circumstances. Processing typically involves sample filtration, lysing, and incubations of $\beta$-D-glucuronidase (GUS) activity for viable culturable (VC) and VBNC E. coli and glucosidase activity for enterococci $[42,99,100]$. However, GUS activity is the most specific, being present in 94-97\% of the E. coli strains tested [99]. By measuring the activity of VC, VBNC, dead bacteria, and free enzymes (depending on the method used), assay preparation methods for GUS enzyme activity quickly consider the activity of each cell for an accurate representation of the total number of cells present, for subsequent measurement [99]. On the other hand, glucosidase activity is particularly useful for enterococci and very promising for this review report's objectives.

The Colilert (for E. coli) and Enterolert (for enterococci) assays, with their own processes, provided final detections of GUS activity for E. coli and glucosidase activity for enterococci through fluorescence viewed under UV lights, and the fluorescing wells were counted as positive reactions. These processes required filtration, selective media, defined substrate technology, and specific reagents. Bushon et al. [101] performed a holding time comparison for Colilert and Enterolert by analysing samples within $8 \mathrm{~h}$ using presence and absence detection methods and within 18-30 h using quantitative methods. They determined that the results for the Enterolert method was not significantly different; however, for Colilert, the quantitative laboratory methods for samples analysed within 18-30 h showed a statistically significantly higher detection frequency than the presence and absence detection method for analysis within $8 \mathrm{~h}$. They identified that result times were at a minimum within $8 \mathrm{~h}$ but Colilert had better results within $18-30 \mathrm{~h}$; and that both methods required multiple processing steps, which limited the efficiency [101].

On the other hand, the Coliplage method directly measures E. coli through GUS activity. It uses a membrane of $47 \mathrm{~mm}$ in diameter for filtrations. They are then incubated, which is followed by detection through the method's fluorescence spectrophotometer at an excitation wavelength of $362 \mathrm{~nm}$ and emission wavelength of $445 \mathrm{~nm}$. This was tested in a field study, when the Coliplage method was applied at 72 coastal sites with 1401 samples, which were collected in the morning; results were 
available in the afternoon [102]. Thus, they were not rapid enough for the proactive management of contamination events. Similarly, Lebaron et al. [43] used GUS activity to measure culturable E. coli when samples were collected in the morning for results in the afternoon; $100 \mathrm{~mL}$ seawater samples were filtered through polycarbonate filters with a pore size of $0.2 \mu \mathrm{m}$ and diameter of $47 \mathrm{~mm}$, and following an incubation, resultant colonies were counted under a UV light. This method is comparable to the most probable number (MPN) microplate method because a significant correlation was found between the $\log$ of GLUase activity and the log of culturable E. coli [43]. However, overestimation of the E. coli concentration and low selectivity were issues found by the Coliplage report in Baudart et al. [102]. The authors explained that their results between typical CBMs did not agree because some marine Vibrio species (detected by direct GUS activity) were the major source of overestimation and should be removed.

Some biosensors successfully detect GUS enzyme activity. A procedure by Rochelet et al. [103] involved a simple preparation of the sample, including a filtration step followed by an incubation period with substrate solution. This worked well in combination with amperometric detection of $E$. coli in wastewater by measuring GUS activity with disposable carbon sensors. The procedure determined E. coli in complex waters in less than $3 \mathrm{~h}$; however, the results had poor sensitivity, and the authors proposed an improvement of increasing the sample volume analysed or enhancing the amperometric response [103]. On the other hand, designed and built by Heery et al. [99], ColiSense is a portable incubating fluorimeter system for onsite detection of surface waters. It is a sensitive purpose-built fluorescence detection and incubation system with three sample chambers for triplicate analysis; it conducts GUS activity assays, incubations, and detections of fluorescence wavelengths (362 nm excitation and $445 \mathrm{~nm}$ emission) for results within a $75 \mathrm{~min}$ period. When tested in the field, $\mathrm{pH}$, temperature, turbidity, and conductivity sensors were attached, and the ColiSense system, with a miniature incubator for the lysing procedure, was placed in a van for transport and powered by the van's battery. Therefore, it was not fully automated, tests made in triplicate required samples to be replaced [99], and the multiple steps and manual processing limited its wider effectiveness.

Generally, to detect E. coli strains, direct enzyme measurements rely on filtration, enzymatic reactions produced by E. coli, GUS, and a medium to yield the fluorogenic product. They also rely on lengthy test procedures and incubations following field sample collection and transportation and non-throughput results; furthermore, GUS activity assays for E. coli should have a selective growth step, as E. coli is not the only microorganism determined by GUS. The assays thus suffer from interferences from other GUS sources, including several freshwater and marine-water algal species [7,99].

\subsubsection{Automated In Situ Biosensors Using a Laboratory Fluorescence Measurement}

Typical automated monitoring systems include miniaturised laboratory-in-vial tools, which provide accurate measurements in steady conditions to improve water quality management. A laboratory-in-vial water monitoring system is a type of biosensor calibrated to detect target indicators, including E. coli and enterococci, with minimal human interaction. With in situ or portable capability, it generally processes samples within its compartments by applying specific bioreagents to samples and, after incubation, measurements made through fluorescence or other optical devices over a specific time frame and/or measurement interval [19,104,105].

An example system is the automatic lab-in-vial E. coli remote tracking tool called ALERT, offered as the in situ analyser ALERT System [106] or a portable analyser ALERT LAB [105]. Both monitor waters for TC, E. coli, and enterococci and offer a measurement range of 4-5 × 10 $0^{5}$ CFU/100 mL, the system is calibrated using bioreagents, incubation temperatures, and fluorescence wavelength detection [105,106]. The ALERT System's waterproof remote-controlled floating buoy determines threshold water quality concentration values and provides alerts when trigger values are exceeded. It can be initiated through either on-demand sampling from cell phone messages or a web-based control page. The measurements can be preprogrammed, and external trigger turbidity and conductivity probes can be established to trigger automatic sampling and measurement operations [19]. Automatic 
sampling is made through the ALERT System's internal vacuum sampling module [106], and consists of seven individual bioreactors, each containing a $25 \mathrm{~mL}$ sampling vial and sampling adapter [19]. After taking all seven individual measurements, a less than 30 min maintenance period is required, which consists of changing the vials, adding fresh reagent to decontaminate the sample tubing and replacing the battery [19]. When the sample in an individual bioreactor is mixed with the specific bioreagent and growth medium, it is incubated. This is followed by a multispectral optical analysis (absorbance and fluorescence), where the fluorescence spectrum is measured at periodic intervals (every two to five minutes). These measurements are logged to the internal data logger and are wirelessly transmitted in real time to a remote data collection and visualisation server. The system has a total response time of less than $8 \mathrm{~h}$, depending on sample characteristics [19], but the response time was identified by Fluidion [106] as being between 1 and $12 \mathrm{~h}$. Angelescu et al. [19] explained the instrument automates all required operations including turbidity correction and signal analysis. Since salinity can inhibit the growth of $E$. coli, a different protocol is implemented for sea or brackish waters, including a dilution step to avoid the development of non-target organisms with similar enzymatic activity presented in seawater, possibly leading to false positives. Furthermore, the reagent has a minimum 3-month stability period when stored in the instrument [19]. Similarly, a self-contained and fully waterproof system with a fully autonomous microbiological alert sensor (AMAS), configurable by a cell phone or cloud interface quantified beach quality monitoring levels (200 CFU/100 mL) for TC and E. coli in less than $10 \mathrm{~h}$. By changing the bioreagent, incubation temperature, and sensor's optical wavelengths, enterococci were monitorable [104]. Any field maintenance required was performed in as little as $15 \mathrm{~min}$, and the system was installed in water in less than $10 \mathrm{~min}$, meaning its setup and maintenance time was similar to that of the ALERT System; however, this work was presented for freshwater only, and seawater monitoring development work was ongoing at the time of the study [104]. Furthermore, both the ALERT and AMAS automated systems use wireless communication protocols for system configuration and data management; both measure E. coli and enterococci concentrations and send automatic alerts if the relevant thresholds are exceeded; and both work under various weather conditions in freshwater, while working with saltwater requires calibration or there is ongoing work to improve it [19,104].

Unfortunately, for both systems, multiple processing and high-throughput sampling is not available, as testing is limited to a number of evaluations before refill; results are not rapid or continuous; salinity is an inhibitor for the growth of E. coli, causing additional dilution and processing; and other constraints include the maintenance requirements and high initial costs of the equipment or system $[19,104]$.

\subsubsection{Portable Field Kit Biosensors Using the Laboratory Fluorescence Measurement}

Portable devices and field kits contain several pieces of equipment and utensils that are necessary for multipositional testing, and they offer promising approaches to water monitoring that are often faster than fully automated devices. The portable ALERT LAB [105] follows the same automatic processing and measurement protocol as the in situ ALERT System [106], but it lacks the automatic sampling function, requiring its bioreagent and sample to be added manually (onsite by personnel) to each vial (bioreactor) prior to measurement. Incubation and fluorescence detection follows, for a result response time within 1-14 h, depending on the sample; this system has six bioreactors, and after six measurements are completed, it requires a maintenance procedure that however takes less than $5 \min [19,105]$.

Similarly, the portable Colifast field kit contains the equipment required to perform any of the three available instrumental analyses; the kit includes the Colifast growth medium, sample vials, utensils, an incubator, and a fluorimeter (the Colifast measuring device), allowing portable detection of E. coli. A $10 \mathrm{~mL}$ sample is manually tested, for results between $15 \mathrm{~min}$ and $2 \mathrm{~h}$, detecting down to $1 \mathrm{CFU} / 100 \mathrm{~mL}[100,107]$. On the other hand, some field kits under development offer very promising result times; one such system is the handheld fluorimeter device by Ferrero et al. [79]. 
This device detects E. coli (in drinking water) in eight minutes; however, after samples are processed with specific cellular biomarkers (the chimeric protein formed by the green fluorescent protein and colicin S4 subunits), their assay required three minutes for filtering and pipetting and five minutes for incubation. Measurement is conducted through the fluorescence-based photomultiplier tube, measuring E. coli when the terminal senses a $395 \mathrm{~nm}$ wavelength emitted by LED light and generating a $509 \mathrm{~nm}$ fluorescence response amplified into an electrical signal. However, the sensor did not conduct incubations, and the authors suggested including a portable incubator device. In addition, sample placement and filtering required personnel, and the preprocessing times were not clearly identified [79].

\subsection{Reagentless and Portable Fluorescence Spectroscopy Measurements}

Portable fluorescence spectroscopy (PFS) devices, incorporated into floating buoys or mobile sensors, utilise the intrinsic fluorescence properties of substances and organisms [34,73,75], and results can be displayed in EEMs (refer to Table A1). Using an experimental PFS device, several reports have found that the fluorescence pair with $280 \mathrm{~nm}$ excitation and $350 \mathrm{~nm}$ emission correlated well to the E. coli presence and biochemical oxygen demand (BOD) of sewage-impacted waters and waters affected by low sanitation $[23,34,76]$. However, although the results were comparable to standard bench-top spectrophotometer results, environmental interferences reduced accuracy [34]. This is also evidenced in a comparison between a more turbid South African site and a less turbid U.K. urban river site: the regression coefficients were respectively 0.55 and 0.81 , highlighting how turbidity greatly affects the accuracy of E. coli detection [76].

Findings have shown that PFS devices are promising because they offer rapid and continuous measurements and can identify E. coli within defined spectral regions; however, PFS devices do not currently offer entirely accurate monitoring of waters. Moreover, careful consideration must be given to factors influencing fluorescence signals, especially local conditions, where interferences from turbidity and other causes negatively affect result accuracy. It is thus necessary to better assess and quantify interferences to overcome poor specificity and sensitivity $[23,34,73,76]$. Improved result accuracy requires minimising or eliminating false positives and false negatives [36]. Promisingly, Sharpe [8] found that both sensitivity and specificity for a PFS device increase with improved or additional optical components or a converging lens. They made this a suggested measure to be incorporated into proposed device developments. In addition, Wildeboer et al. [108] through algorithm development and computational analysis, found that a software controlled setup provided better detector sensitivity with corrections for background signal and blank samples.

\subsubsection{Sensitivity}

The sensitivity of a monitoring tool is defined by the proportion of target organisms that can be detected within a test matrix, meaning PFS devices are not sensitive if they do not detect $E$. coli when E. coli exists $[36,109,110]$. The sensitivity of results from a PFS device influences its ability to correctly identify E. coli using the correlation between fluorescence intensity and E. coli [109,110]. Additionally, sensitivity is critical when detecting very low FIB concentrations. Gaulier et al. [111] successfully managed low sensitivity using a fluorescence depletion approach, developing a probe to separate the signal between organic and bacterial pollutants; however, this method was not simple in its construction and required resource-heavy equipment. Environmental site-specific interferences and sample matrix effects can interfere with the accuracy of measurements of $E$. coli and enterococci and invalidate the results. This is more troublesome when fluorescence tools are used without preprocessing, culturing, or reagents in samples $[23,36,73,76,111]$.

\subsubsection{Specificity}

Specificity is the ability to discriminate between target organisms and other organisms or substances within a detection matrix $[36,109,110]$. Low specificity in PFS devices can result from issues of overlapping fluorescence intensity between E. coli and enterococci and other substances 
present in water. These issues can be caused by microbiological processing of natural organic matter, oil spills, and polycyclic aromatic hydrocarbons (PAHs) [23,34,76]. As documented by Baker et al. [76], the main sources of low specificity in their results were likely catchment specific factors including: microbial activity, pollution sources, oil spills, diesel, and PAHs. Other reports found that dissolved organic matter (DOM) and tryptophan-like fluorescence (TLF) disturbed the specificity of fluorescence detection devices and optical sensors for E. coli, and additional considerations must be made for particles, bubbles, the bacterial detection range, and biofouling $[23,73,76]$.

\section{Spectral Signature of E. coli and Enterococci}

Fluorescent spectrum signatures exist for bacterial species including E. coli (and likely enterococci), but these signatures might in turn be dependent on the cellular or extracellular accumulation of the fluorescent material, as suggested by Sharpe [8]. However, several reports indicate the correctness of the general agreement between excitation and emission wavelengths for E. coli; enterococci require further investigation.

Through absorption spectroscopy, Kiefer et al. [64] identified an accurate characterisation of the absorption spectra for $E$. coli cells in suspensions (without reagents), when samples were prepared with and without inactivation procedures, including heat and high pressure. Their computational analysis found that $420 \mathrm{~nm}$ provided high-sensitivity quantitative determination of cell concentration, in the range 350-400 nm distinguished between cells with a damaged membrane and those with an undamaged membrane, and between 800 and $900 \mathrm{~nm}$ detected cell contents released after the destruction of the cell membrane, all under laboratory conditions and process time [64]. On the other hand, Walck [112] used absorption spectroscopy and fluorescence spectroscopy to define the fluorescence spectrum of $E$. coli in samples diluted with distilled water, thus finding a true excitation peak of $280 \mathrm{~nm}$ and a target emission wavelength of $338 \mathrm{~nm}$; their method detected that spectral signatures of E. coli existed in the peak-T region $[34,73,76]$. This was further evidenced when a principal component analysis (PCA) performed by Baker et al. [76] confirmed the general correlation between E. coli concentration and direct fluorescence intensity at a specific wavelength pair (within the peak-T region); however, at individual catchments, the PCA returned variable fluorescence intensity relationships attributed to optical interferences. Cumberland et al. [34] tested river and effluent samples for the fixed-wavelength pair with $280 \mathrm{~nm}$ excitation and $360 \mathrm{~nm}$ emission and an intensity of peak-T2 and found a correlation of $R^{2}=0.72$ for uncultured E. coli dilutions. Baker et al. [76] used the pair with $280 \mathrm{~nm}$ excitation and $350 \mathrm{~nm}$ emission for E. coli and produced an overall log correlation between $E$. coli and fluorescence intensity of $r=0.74$. However, they saw the accuracy disturbed by catchment-specific interferences. This was explained by Carstea et al. [73] when in situ peak-T fluorescence correlated with $E$. coli (only at sites with sanitation problems) showed $R^{2}=0.71-0.95$ for freshwater, $R^{2}=0.59-0.77$ for groundwater, and $R^{2}=0.66$ for marine water, but only at sites with sanitation problems. Thus, in groundwater, marine, or coastal waters, the peak-T-BOD relationship returns a lower correlation, potentially due to the presence of non-microbial fluorophore and/or aquatic organisms [73]. Whether this or other environmental interferences in any water can be resolved is a question for further research.

\section{Catchment Specific Factors}

Baker et al. [76] developed a PCA, and their discussion identified that catchment specific factors were likely to be more significant than optical interferences caused by $\mathrm{pH}$, temperature, and turbidity. Their data also suggested that microbial activity increased fluorescence intensity without the presence of $E$. coli and this might be observed in eutrophicated systems without sewage contamination. This includes non-faecal pollution sources, such as oil spills, and PAHs, which emit fluorescence in the EEM regions, and will all affect the E. coli-fluorescence intensity relationship [76]. 


\section{Engine Oil or Diesel}

Fluorescence spectroscopy techniques are used to monitor riverine organic matter and diesel pollution [72], and laboratory studies have found that commercial diesel and EPA refined oils have a fluorescence emission between 340 and $400 \mathrm{~nm}$ [113]. Carstea et al. [73] reviewed an oil fluorescence relationship analysis that returned the correlation of $r=0.96$ between peak-T fluorescence and oil compounds obtained in a simulated oil-pollution event; however, the myriad of fluorophores in marine waters overlapping in the peak-T region made it difficult to identify a specific compound. They concluded that three PAHs commonly present during an oil spill display a fluorescence signal close to or in the peak-T region: specifically, fluorene (excitation/emission-260/315 nm), naphthalene (excitation/emission-275/340 nm), and phenanthrene (excitation/emission-255/360 nm). PAHs are the predominant detection disturbance for E. coli during an oil spill or diesel event; these display excitation and emission intensities of $255 \mathrm{~nm}$ and $360 \mathrm{~nm}$, respectively overlapping TLF and E. coli. In addition, since temperature alters oil and diesel viscosity in water, warmer or cooler water respectively causes less or more pronounced effects on fluorescence intensity readings when detecting TLF and E. coli $[73,76,114]$.

\section{Tryptophan-Like Fluorescence}

Tryptophan-like fluorescence detection through fluorescence-based tools has been used as a proxy for E. coli; TLF intensity correlates well with E. coli concentrations [23,115]. However, reports have shown that E. coli dominates TLF in high concentrations, making E. coli the dominant fluorescence product in the given detectable region; this suggests that depending on concentrations, both E. coli and tryptophan are indirectly measured in different proportions. This can therefore be a specificity issue for PFS devices for E. coli (and TLF), when at low concentrations $[23,76,116]$, such as when monitoring drinking waters.

\subsubsection{Interferences}

The following interferences cause disturbance in the measurement of portable spectroscopy devices because they increase or typically dampen fluorescence intensity measurements.

\section{The Inner Filtering Effect}

The inner filtering effect (IFE) of fluorescence measurements is a matrix effect that causes an apparent decrease in emission quantum yield or a distortion of the band shape, because IFE results from the absorption of excited and emitted photons by the sample matrix or, at high concentrations, the compound or the fluorophore itself $[70,114,117]$. The inner filtering effect is a significant issue requiring removal of data from the results of PFS devices because IFE limits the detection accuracy resulting from light absorption, decreases the excitation intensity at the point of excitation, and generally provides tempered readings for fluorescence devices $[73,118,119]$. Chen et al. [118] found that IFE for FIB fluorophores is more pronounced in complex biological environments resulting from surrounding environmental interferences. Similarly, for the fluorescence detection of DOM, de Oliveira et al. [119] noticed that IFE affected the readings of their commercial fluorescent DOM (fDOM) sensor, and consequently, they developed a compensation algorithm.

\section{Turbidity}

Turbidity is a measure of the cloudiness of a body of water from light scatter and absorption, which alter reflection patterns through dispersal; this is a significant interference for PFS water monitoring and, along with nutrient levels, is usually higher following heavy rainfall $[76,119,120]$. The adverse effect of turbidity on PFS devices was identified by Khamis et al. [121] when detecting TLF; their spectral results returned increased fluorescence intensity with turbidity levels. They stated this was not clearly diagnosable but also suggested it was likely a result of different particle sizes between clay and silt materials and other items colluding in the water; they also identified the need for 
site-specific and sensor-specific turbidity compensation. The increased fluorescence intensity found by Khamis et al. [121] was strange, as turbidity typically reduces the signal, as evidenced in a study by de Oliveira et al. [119] using fDOM sensors. This is because, as water turbidity increases, the excitation light emitted by the PFS sensor scatters and reduces the amount of light in the sample volume that is available to excite the target substance.

Baker et al. [76] identified the strong relationship between log fluorescence intensity and log E. coli and expressed turbidity's negative influence on fluorescence intensity. Furthermore, the negative effects of turbidity effects were identified by Bertone et al. [122] on fluorescence probes used for the monitoring of cyanobacteria. They used a submersible fluorescence phycocyanin (PC) probe to show that turbidity >50 NTU could make in situ PC fluorescence measurements ineffective. All these examples show the need to remove these effects where possible.

\section{Temperature}

Fluorescence intensity is highly dependent on temperature, and this is evidenced by increased thermal quenching of temperature prompts on fluorescence resulting in lower readings [117,122]. This occurred in several reports. Baker et al. [76] discussed interferences with their PFS device for $E$. coli detection and expressed that the thermal quenching effects of temperature could cause an approximate $30 \%$ variation in fluorescence intensity over a $35{ }^{\circ} \mathrm{C}$ temperature range and were likely to explain less than $5 \%$ of the variability in the dataset. On the other hand, de Oliveira et al. [119] recorded a smaller quenching effect on their commercial fDOM sensor, where thermal quenching resulted in an approximate $10 \%$ change in fluorescence intensity over the $35{ }^{\circ} \mathrm{C}$ temperature range. Sorensen et al. [115] discussed environmental factors that can influence the intensity determined by in situ fluorimeters that target TLF. They found that thermal quenching might have been limited to $10-20 \%$ over the typical temperature range based on previous results using bacterial cultures. This was supported by Khamis et al. [121] when they found from their field trials with in situ TLF fluorimeters that TLF was inversely related to water temperature. Wasswa and Mladenov [114] also stated that typical fluorescence sensors were affected by temperature, which influences the photophysical properties of the fluorescence. The results from their controlled temperature experiments showed for all samples that increased temperature was inversely proportional to fDOM and TLF fluorescence intensities but that this was more pronounced for TLF than fDOM fluorescence.

$\mathrm{pH}$

The $\mathrm{pH}$ of a water sample might increase or decrease the fluorescence signal depending on the $\mathrm{pH}$ range, the water sample's characteristics and the peak of fluorescence measured $[73,117]$. Henderson et al. [117] examined fluorescence as a potential monitoring tool for organic matter and found that $\mathrm{pH}$ could affect spectral shapes of humic and fulvic-like substances and, to a lesser extent, TLF; they found $\mathrm{pH}$ effects to be generally minor or at least controllable. This was expressed in their summary evaluation of the relative importance of matrix effects to implementing fluorescence as a monitoring tool. The evaluation shows that typical advanced treated water values with $\mathrm{pH} 6-8 \mathrm{had}$ an anticipated impact (based on literature) of an increase in fluorescence intensity of 0 to $<30 \%$ for all peaks. However, this was a reversible effect in the $\mathrm{pH}$ range of 2-12, and it was insignificant when the $\mathrm{pH}$ range was small ( $<2$ units) [117]. Other reports have shown that typically, $\mathrm{pH}$ affects the E. coli-fluorescence intensity relationship for PFS devices when other optical interferences collude with $\mathrm{pH}$ [76]. The $\mathrm{pH}$ quenching of fluorescence intensity was reported by Baker et al. [123] to produce a $<40 \%$ reduction in fluorescence intensity for a $4 \mathrm{pH}$ unit change in their freshwater organic matter assessment. It likely explains less than $20 \%$ variability in the measurement dataset by Baker et al. [76] for E. coli fluorescence. However, Baker et al. [76] expressed in their discussion that catchment specific factors are likely to be more significant. 


\section{Salinity}

De Oliveira et al. [119] tested the effects of high salinity (due to its increase when concentrating DOM) on fDOM readings and found that no variations in readings were noticed. Bertone et al. [124] pointed out that based on previous research studies, salinity alters the intramolecular reaction, interferes with fDOM readings, and can cause quenching on fDOM measurements; however, in terms of potential quenching when testing freshwater systems, salinity levels should be negligible. In marine waters, conversely, Carstea et al. [73] found several fluorophores overlapping in the peak-T region, and it is difficult to pinpoint a specific compound. Thus, interference with fluorescence, rather than due to salinity, was likely due to the presence of marine aquatic items and organisms.

\section{Discussion}

The preparation- and measurement-type monitoring approaches for E. coli and enterococci are summarised in Table A1 (see Appendix A), displaying their features, strengths, and barriers. Throughout the review process, the shorter and longer result times were documented. Significantly, several technologies performed tests in situ, with reasonable assessment times. However, even in the best case, results took between 1 and $24 \mathrm{~h}$. Some results could be obtained in less than $10 \mathrm{~min}$, but these tests were not available for repeated volume assessments and are often single use only; additionally, many of these simple and quick assessments were not made for in situ usage or varied environment and bacterial species. The variations in time to result are expressed in Figure 2, which is a histogram of shorter and longer result times, including an additional plot magnifying the fastest detection results.

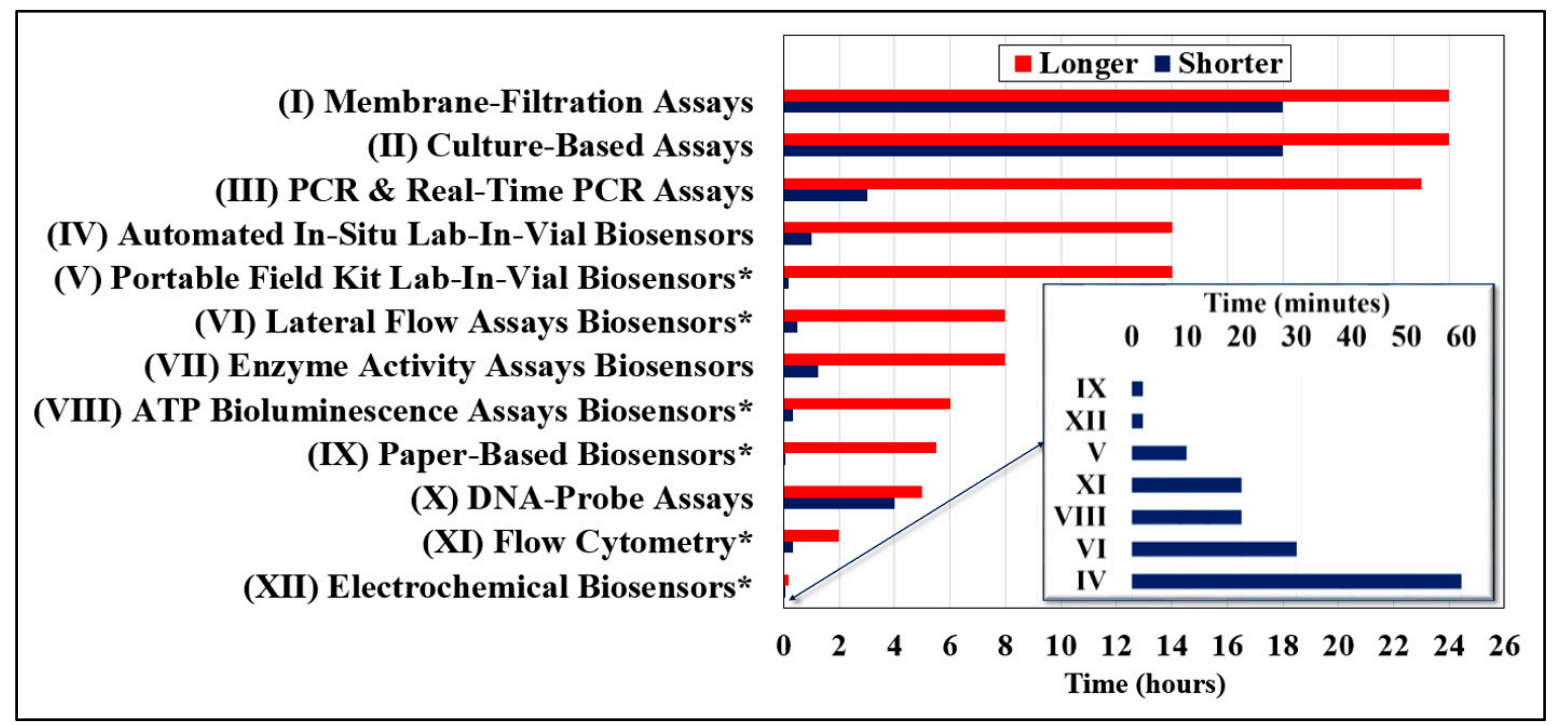

Figure 2. Histogram of times to result of review-identified monitoring tools. Includes an additional plot (lower right) of the fastest times in minutes; these times $\left(^{*}\right)$ potentially exclude preprocessing.

However, Figure 2 provides the currently expected times to a result, and more information should be obtained by contacting the authors of the references provided in the previous sections. Additionally, certain assumptions were associated with the shorter times $\left(^{*}\right)$, when the reports did not specify the time required to preprocess samples. Whether the tool was reusable or usable in situ was identified and referenced in this review paper.

\subsection{Identification of Gap in E. coli and Enterococci Monitoring}

A current limitation of several assessment technologies analysed in this paper relates to the considerable amount of time required to obtain results; generally, this is because most of the technologies rely on manual sampling, which is often time consuming and resource intensive. 
Moreover, sampling and culturing preparation-type assay methods require samples and reagents to be prepared, and screenings can be disturbed by site-specific influences and low sensitivity, specificity, or robustness. Results are often derived in laboratories, thus also requiring transportation. The automated tools are often costly to purchase and maintain, and results can sometimes be inaccurate while being non-continuous and non-real-time. The portable fluorescence tools and field kits offer real-time monitoring, but for E. coli and enterococci, they have relied thus far on reagents or preprocesses, and similarly, they have non-rapid and non-continuous results. Regarding the fluorescence-based detection devices currently offering monitoring of $E$. coli and enterococci without reagents or preprocesses, their readings are disturbed by interferences and false-positive reactions.

Furthermore, this review paper has highlighted the potential to properly discern E. coli and enterococci fluorescence in complex media, prompted by the correlation between the peak-T region and E. coli in waters with poor sanitation $[23,34,73,76]$. The goal of discerning this fluorescence is to develop a portable interference-free fluorescence-based detection device based on this identified fluorescence. Such a fluorimeter should offer a less resource-heavy approach than existing fluorimeters to long-term in situ monitoring assessments of $E$. coli and enterococci, with rapid and accurate high-frequency results. This should be usable in situ and remotely deployable over the long term, with near real-time results. However, optical readings should be corrected for reduced specificity caused by target bacteria wavelengths, overlapping fluorescence spectra in catchment specific waters, TLF, engine oil, or diesel; and interferences from the inner filtering effect, turbidity, temperature, $\mathrm{pH}$, and salinity.

Thus so far, despite promising, such a fluorescence-based method would not provide accurate real-time FIB measurement in situ due to technical and accuracy limitations.

\subsection{A Research Framework towards Reliable and Remote Fluorescence-Based Monitoring of E. coli and Enterococci}

As shown in this review paper, several specificity issues and interferences affect the fluorescence intensity readings, and previously conducted studies have identified the potential to model and associate fluorescence to particles and then project this into a detection mechanism. Compared to other monitoring types, portable fluorimeter technologies are flexible and economical; however, refined fluorescence detectors of $E$. coli (or enterococci) in water are currently not available without preprocesses, reagents, or assays, despite the critical importance of finding an effective detector that does not have these requirements. Since the peak-T region of EEM plots is useful for E. coli (and likely enterococci), research on this region is the most promising direction for developing a detector with the desired properties considering the proxy relationship between the peak-T region and E. coli in water with poor sanitation $[73,76]$. The objectives for the fluorescence-based sensor are to provide continuously monitored data recordings of relevant fluorescence wavelengths, and if the signal threshold is exceeded, this should then trigger an alert. We recommend, following the successful development of a PFS tool, an additional verification sensor component would refine the specificity of the proposed fluorescence-monitoring tool and could be used to develop a hybrid system.

\subsection{Characterisation of a Hybrid Sensor}

The proposed hybrid system involves a fluorescence sensor (Sensor \#1), which is semiattached to an additional sensor (Sensor \#2), as shown in Figure 3. Sensor \#2 is for verification purposes, and is deployed or active only when Sensor \#1 issues a warning; it is therefore not continuously active. This aims to solve selectivity issues. Since it is triggered only sporadically, the amount of maintenance/reagents required is reduced, effectively enabling the hybrid sensor to function autonomously in a reservoir or river for weeks or months. 


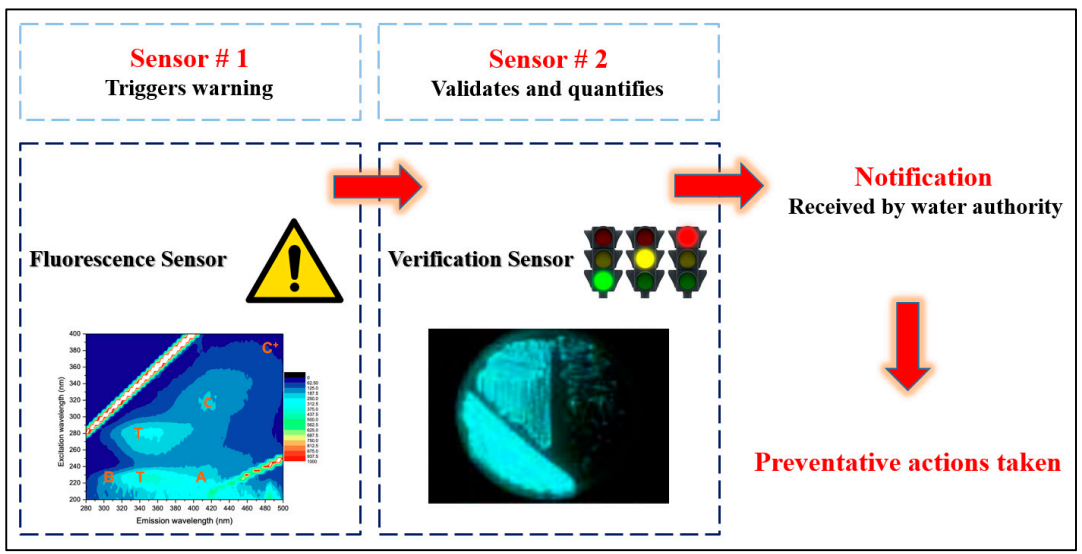

Figure 3. Functioning principles of a hybrid sensor for faecal indicator bacteria.

The steps in the process for Sensor \#2 are the following:

- Is Sensor \#1 triggered? (Yes/No/Check Again);

- If Yes, then the detection is verified by Sensor \#2;

- If No, then no process occurs, and Sensor \#1 continues its monitoring processes.

The next sections provide more detail about the two specific sensors, based on the knowledge gathered through this review study. Whilst a few options in terms of the technology for "Sensor \#2" are proposed, the main issues with Sensor \#1 (fluorescence-based), in addition to selectivity, is low accuracy due to optical interferences. Hence, methods to improve its accuracy are discussed.

\subsection{Fluorescence Sensor (Sensor \#1)}

\subsubsection{Correction Methods for Specificity}

Robust Identification of E. coli and/or Enterococci Spectral Signatures

Fluorescence intensities for E. coli and/or enterococci wavelengths should be documented guided by prior investigations. The first promising result for E. coli samples diluted with distilled water was described by Walck [112] who used absorption spectroscopy, fluorescence spectroscopy, and PCA to define the fluorescence spectrum of E. coli, including an excitation and emission wavelength maxima and the excitation-emission matrix (EEM). The EEM for living E. coli (then repeated for dead) was plotted by taking 21 fluorescence spectra, with excitation wavelengths increasing from 220 to $320 \mathrm{~nm}$ (per $5 \mathrm{~nm}$ ), and plotting them in 3D. The peak absorption wavelength was found to be $260 \mathrm{~nm}$. It was then used as an initial excitation wavelength to develop the fluorescence and excitation spectra of E. coli. Finally, a true excitation peak of $280 \mathrm{~nm}$ and a target emission wavelength of $338 \mathrm{~nm}$ were identified [112]. In Cumberland et al. [34], a portable LED spectrophotometer successfully used the fixed-wavelength pair with an intensity of peak-T2 (280 nm excitation and $360 \mathrm{~nm}$ emission). Similarly, Baker et al. [76] used the $280 \mathrm{~nm}$ excitation and $350 \mathrm{~nm}$ emission pair, but the accuracy of the spectrophotometer was disturbed by catchment-specific interference. Previously, Bharadwaj et al. [125] claimed that their portable optical setup with a UV LED, a spectrometer, and a U-bent fibre-optic probe, with a core diameter of $200 \mu \mathrm{m}$, obtained label-free detection of $E$. coli at a $280 \mathrm{~nm}$ wavelength.

Previous documentation has found and used similar intensities; while the excitation wavelength was $280 \mathrm{~nm}$, the emission wavelength varied. Thus, more research is recommended to verify the excitation and emission wavelengths. We suggest following similar collection processes to Walck [112] and recording intensities of known E. coli (and enterococci) concentrations in waters using absorption and fluorescence spectroscopy. This will help to correctly identify E. coli (and enterococci) and distinguish them from other fluorescing substances. 


\section{Distinguish/Remove Overlapping Fluorescence Spectra}

This review paper recommends conducting a site-specific sampling program and recording the typical fluorescence excitation and emission intensities of typical substances in those waters. Spectral deconvolution is one method proposed to reduce catchment specific factors. This method was expressed in Mahmud et al. [126]. They identified nitrate in water by direct UV spectrophotometry, and to solve interferences and overlap high-resolution spectral deconvolution techniques separated the nitrate signal from nitrite and bromide ions and other interfering ions/compounds in seawater. There is computer software that allows the user to perform automatic or manual spectral deconvolution of individual wavelengths $[127,128]$.

Previous studies have also successfully addressed interferences between fluorescent regions by investigating ratios of fluorescent peaks or through the parallel factor analysis (PARAFAC) modelling approach [116,129]. A DOM assessment using fluorescence spectroscopy by Heibati et al. [130] identified that independent signals could be quantified using the PARAFAC algorithm, which identifies the best-fitting excitation and emission spectra for each independent signal and its relative concentration in each sample. Carstea et al. [73] reported improved results by using hybrid field fluorimeters, operating at wavelengths specific to each fluorophore. On the other hand, a more promising approach considered the fluorescence properties of diesel pollutants, when detected during real-time monitoring, and analysed the use of both peak-picking techniques and self-organising maps (SOM) [113]. As identified by Carstea et al. [113], SOMs are unsupervised neural network algorithms. Self-organising maps are a tool for fluorescence data analysis (of EEM data), and calibration can be carried out in Matlab 7.7 with the statistics toolbox 6.0.1 and neural network toolbox 6.0.1. Self-organising maps can provide an on-line quantitative and qualitative evaluation of fluorescence data and effective detection of organic pollutants (diesel pollution) [113].

We suggest implementing spectral deconvolution, PARAFAC, SOM, or other signal disaggregation techniques to attempt to account for the confounding factor such as diesel or TLF. This can reduce the selectivity issues and further limit the need for operation of a verification sensor.

\subsubsection{Correction Methods for Interferences}

\section{Correction Methods for the Inner Filtering Effect}

The IFE in fluorescence measurement requires mitigation measures to remove or reduce the error through correction factors applied to a calibration model or by diluting the water $[118,119]$. Assuming disturbances are consistent and not too large, another alternative is to leave the data uncorrected and use the resultant wavelength-dependant non-linear relationship between fluorescence intensity and concentration; however, that is not always possible [117]. Henderson et al. [117] found that IFE can be compensated using an empirical correction based on the absorbance profile of the given sample. Chen et al. [118] found that compensating IFE and restoring the linear relationship between the fluorescence intensity of a fluorescent substance and its concentration required compensation (for any fluorescing material). The authors introduced an experimentally verified correction equation to determine the corrected maximum fluorescence intensity [118]:

$$
F_{\text {corr }}=F_{o b s} \times 10^{(A e x+A e m) / 2} \text {, }
$$

where $F_{o b s}$ is the maximum fluorescence intensity being measured, $F_{c o r r}$ is the corrected maximum fluorescence intensity following correction for IFE, and $A_{e x}$ and $A_{e m}$ are absorbances at the excitation wavelength $\left(l_{\mathrm{ex}}\right)$ and maximum emission wavelength $\left(l_{\mathrm{em}}\right)$, respectively. de Oliveira et al. [119] successfully used a sequential data-driven model to compensate their initial readings of fDOM using $\mathrm{UV}_{254}$ and proved that accurate and reliable corrections were possible for raw FDOM against IFE interferences, though requiring a $\mathrm{UV}_{254}$ monitoring tool. Similarly, monitoring DOM, Carstea et al. [72] found that the best correction tool for IFE (for lake water samples but not wastewater) was the 
absorbance-based approach, while for wastewater studies, the two preferred methods to reduce IFE were dilution and post-measurement mathematical correction. While dilution correction could be an option for E. coli (and enterococci), testing would be required in situ, and automated pumping would therefore be required to draw clear water into the sample with extra equipment and water. This might overly complicate fluorescence assessments.

For Sensor \#1, this review recommends developing a simple data post-processing correction through absorbance as identified by Chen et al. [118] with an additional monitoring tool and calibration of the UV sensor measurements; if a particular absorbance value were found for $E$. coli (and enterococci), then the value from the absorbance monitoring tool could be integrated into a system's calibration through experimentation.

Correction Methods for Turbidity Interference

There is potential to quantify and account for turbidity interferences on optical devices by developing calibration models for sensors. One promising approach is a sequential data-driven model used to compensate initial readings of an fDOM probe. As expressed by de Oliveira et al. [119], this shows that accurate and reliable corrections are possible for raw fDOM readings from turbidity interferences. Their model outperformed other linear and non-linear multivariate regression models; however, they recommended further work to develop a more generalised compensation model following site-specific development data $[119,124]$, as site-specific particle size distributions and other features can cause different degrees of interference.

Sorensen et al. [23] found that turbidity interference on TLF detections could be partially addressed by widening the separation between the excitation and emission wavelengths and reducing the broad excitation and emission wavelengths to maximise fluorescent output. Whereas, Carstea et al. [73] identified that individual site-specific correction factors made possible through turbidity meters paired with fluorimeters efficiently addressed turbidity interferences on fDOM sensors in rivers and streams. Khamis et al. [131] stressed the importance of calibrating sensors using sediment collected from the field location. Similarly, Khamis et al. [121] explained that turbidity interferences were due to numerous factors including site-specific activity, and if very high turbidity was expected, inline filtration might be required. They tested compensation models for in situ TLF fluorimeters in a stream, against interferences from temperature quenching and turbidity (for silt and clay). They found the relationship between laboratory and in situ fluorescence was good and recommended compensation models for certain applications (e.g., surface water monitoring).

Sensor \#1 should be paired with a turbidity probe to quantify site-specific interference and develop correction algorithms. The second-order and third-order polynomial by Khamis et al. [121] would be sufficient to model the data with Equation (2) for silt and Equation (3) for clay:

$$
\begin{gathered}
c f=a+a b+a^{2}+a^{2} b^{2}+b^{3}+a^{3} b^{2}, \\
c f=a+a b+a^{2}+a^{2} b^{2},
\end{gathered}
$$

where $c f$ is the correction factor, $a$ is turbidity NTU, and $b$ is the difference between the measured and standard tryptophan signal [121]. Our paper suggests testing the turbidity correction factor Equations (2) and (3) or developing regression models similar to those by de Oliveira et al. [119].

\section{Correction Methods for Temperature Interference}

Thermal quenching of fluorescence can cause interferences with optical devices when used in situ. Several reports offered correction algorithms for either removal or reduction of thermal quenching. Concerning fDOM, Henderson et al. [117] found that temperature effects cause fluorescence quenching and that it is a linear and reversible effect that can be overcome through correction factors. This is supported by de Oliveira et al. [119], who found that temperature has a linear inverse relationship with $\mathrm{fDOM}$, and they developed and then tested their own sequential data-driven model to compensate the 
initial readings of an fDOM probe. They described how their model allows for accurate and reliable corrections of raw fDOM readings against temperature interference. Sorensen et al. [23] discussed that temperature quenching of dissolved tryptophan (TLF) was linear, but in field studies, quenching occurred at different rates in different water types; therefore, quenching should be individually corrected. Carstea et al. [73] also found that TLF was susceptible to thermal quenching and that temperature corrections in referenced reports could reduce its effects. Khamis et al. [121] introduced a compensation algorithm for TLF in freshwater applications to quantify temperature quenching interferences, and they significantly improved the agreement between in situ and laboratory readings. Watras et al. [132] developed a temperature compensation model for fDOM fluorimeters. Wasswa and Mladenov [114] built upon that to correct temperature effects on TLF; they expressed a relationship between TLF fluorescence intensity and temperature compensation constants for all water types and found that using a root mean square error (RMSE) model with TLF fluorescence data, produced the best fit to the reference temperature for three of their tested fluorescence sensors.

Our paper suggests Sensor \#1 should be paired with a temperature sensor to correct readings.

Correction Methods for $\mathrm{pH}$ Interference

Sampled water might cause a slight interference with and a minor impact on fDOM fluorescence intensity measurements when it is in the typical $\mathrm{pH}$ range of natural water ( $\mathrm{pH} 5-9$ ) [119]. Since $\mathrm{pH}$ effects have been found to cause interference with E. coli fluorescence intensity $[76,123]$, pH effects should be accounted for.

The $\mathrm{pH}$ can be determined using $\mathrm{pH}$ meters [76], and to better quantify the $\mathrm{pH}$ relationship against E. coli fluorescence emission, this review paper recommends $\mathrm{pH}$-relevant corrections be developed by modelling the correlation between the measured fluorescence intensity of $E$. coli against a wide $\mathrm{pH}$ range.

Correction Methods for Salinity Interference

There is potential to gain higher accuracy and improved data from fluorescence tools by developing salinity compensation models $[124,133]$. Salinity can be determined using salinity meters and electrical conductivity meters [76]. Carstea et al. [73] found that peak-C (humic-like or chromophoric DOM) in the blue and green fluorescence region (excitation 300-350 and emission 400-500 nm) can be an indirect proxy for salinity and for marine waters, and it is possible to use these indicators to calibrate compensation models.

Salinity can be an inhibitor to the growth of E. coli, and protocols might be needed for high-saline waters [19]. Salinity/conductivity probes should be paired with Sensor \#1 to quantify and mitigate this issue with data-driven models developed based on experimental data.

\subsection{Verification Sensor (Sensor \#2)}

Despite the improved accuracy and reliability of a fluorescence sensor (Sensor \#1) for E. coli and enterococci, results might remain disturbed by false positives and interferences; this necessitates a method of verification (Sensor \#2) using pre-existing technologies, which must work remotely and in real time. Any Sensor \#2 verification should become active only following an alarm triggered by Sensor \#1. The following list identifies promising suggestions for an approach to Sensor \#2 based on three questions: (1) Can it be automated? (2) Can it be miniaturised? (3) Is it efficient?

I. The smartphone detection of E. coli from field water samples on paper microfluidics was presented by Park and Yoon [91]; their three-channel paper chip provides low- and high-concentration detection of field samples. E. coli antigens promote travel through the paper fibres (aided by capillary action), while other items in the water (dust, soil, and algae particles) are filtered out. The total assay time is about $90 \mathrm{~s}$, and the sample size is $7 \mu \mathrm{L}$; the smartphone camera (requiring a gyro-sensor software application to be installed) detects E. coli from an angle onto the paper chip, which contains preloaded antibody-conjugated beads 
(the shelf-life of the beads is 8 weeks at room temperature). The paper chip is not described as reusable [91]. (1) This method is not automated, and because it uses a smartphone camera, including a battery, in the water, it is not convenient and probably not possible to be used in situ unless adjustments are made, including another method of chip visualisation. However, the processes are not complicated (sample placement and phone app detection). (2) The detection surface chip is miniaturised. (3) This method is accurate, but it was not described as reusable; therefore, it would require several individual chips to be preloaded in the device, with automated processing.

II. Fast and accurate detection of E. coli from a water droplet by electric field effects and micro-Raman spectroscopy was presented by Liao et al. [96]; their surface-based detection method uses alternating-current electrokinetic effects to capture E. coli (K12) species (at concentrations as low as $10^{2}$ bacteria/mL from $50 \mu \mathrm{L}$ samples). This method is label free without the need for signal amplification, and results are obtained within several minutes. (1) This method is not automated, but its processes are not complicated (sample placement and online detection), and the authors worked on a flow-through microfluidic system for online sample monitoring. (2) It is miniaturised. (3) It is efficient and accurate, but testing currently requires collection personnel and the authors did not identify whether it was reusable. The authors identified that it could be improved with a water-immersion lens to eliminate the washing and drying steps; also, by using monoclonal antibodies to improve selectivity and using an immobilisation method to increase the antibody surface density [96].

III. The rapid detection of single E. coli bacteria using a graphene-based field-effect transistor device by Thakur et al. [89] proposes to return single-cell E. coli detection within $50 \mathrm{~s}$ for $1 \mu \mathrm{L}$ samples (it potentially detects single $E$. coli cells in a large sample volume only when coupled with a suitable filtration setup). This thermally reduced graphene-oxide-based field-effect transistor, passivated with an ultrathin layer of $\mathrm{Al}_{2} \mathrm{O}_{3}$, provides label-free results at a low cost; however, it is currently only for one-time use, although it has the possibility of being regenerated using a suitable regeneration buffer [89]. (1) This method is not automated, and the process requires a filtration system and then detection; however, this is a significant limitation because an in situ remote filtration system will eventually become clogged, depending on how many checks Sensor \#2 must perform. It would also require regular maintenance. (2) It is miniaturised. (3) It is not very efficient because it is not reusable, but it is low cost and accurate.

IV. A portable handheld fluorimeter developed by Ferrero et al. [79] for drinking water detects chimeric proteins after specifically recognising and binding to E. coli cells; results are obtained in eight minutes (five minutes for incubation at room temperature and three minutes for filtering $2 \mathrm{~L}$ of water and measurement). Filters are inverted to recover E. coli cells (with PBS from the filter membrane). The fluorimeter measures the $E$. coli cells with a detection range of 20-1000 E. coli CFU/mL [79]. The preparation of the assay with filtering and incubation is external to the fluorimeter, and the manual placement of the sample is required for measurement. (1) This method is not automated, but the process is not complicated (filtering, incubation at room temperature, and sample placement). Similar to Suggestion III, this method requires an in situ remote filtration system and then detection, which is a significant limitation, as it may become clogged quickly depending on the checks performed by Sensor \#2. (2) It can be miniaturised; a final recovery had $2 \mathrm{~mL}$ in the cuvette after filtering $2 \mathrm{~L}$ of rural spring water (0.2 $\mu \mathrm{m}$ pore size). (3) It is efficient and accurate, but it tested $2 \mathrm{~L}$ filtered to a $2 \mathrm{~mL}$ sample.

V. A preparation method assay protocol developed by Briciu-Burghina et al. [44] has a result time of $75 \mathrm{~min}$ for the detection of E. coli using GUS activity. The two main steps are (i) sample preparation using syringe filters with a dual purpose (the recovery and preconcentration of E. coli) and (ii) measuring of GUS activity. Syringe filtration and recovery are conducted onsite. The incubation of the lysing syringe filter requires a portable incubator, and detection requires a handheld portable fluorimeter [44]. (1) This method is not automated, but it is also 
not complex (filtering, incubation, and sample placement). (2) It is not miniaturised, but the Briciu-Burghina et al. [44] group used a portable miniaturised fluorimeter (ColiSense) with incubation capabilities, designed for the protocol presented, and successfully delivered results onsite within a $75 \mathrm{~min}$ period; and it has the potential to be automated into a flow-through system. (3) The method offers high accuracy and short time to result but requires six steps, with filtration, incubation, and measurement, so it is not very efficient.

VI. The reporter bacteriophage T7NLC identified by Hinkley et al. [134] utilises NanoLuc::CBM fusion for ultrasensitive detection of E. coli in drinking water. E. coli is infected with T7NLC and cellulose. The bacteriophage triggers Nluc luciferase production and light, for a limit of detection of $<10 \mathrm{CFU} / \mathrm{mL}$ in $3 \mathrm{~h}$. However, it requires several critical steps, including a pre-enrichment step. The phage requires an actively growing host for successful infection. The $60 \mathrm{~min}\left(37^{\circ} \mathrm{C}, 225 \mathrm{rpm}\right)$ pre-enrichment step resuscitates bacterial cells; following this, another incubation of phage stock and cellulose $\left(37^{\circ} \mathrm{C}, 225 \mathrm{rpm}\right)$ allows phage infection and reporter enzyme production. Currently, (1) this method is a preparation assay and is not currently automated, but the steps are not complicated. (2) It is not miniaturised; however, there are other methods that undertake similar processing, and this method could be miniaturised in a newly developed system. (3) It is efficient and offers high accuracy [134], but it is a proposal sensor that requires development.

\section{Conclusions}

This comprehensive review has highlighted that researchers and professionals in the water and sanitary engineering field have long recognised the need for a rapid and effective method of detecting FIB; however, traditional tests are time consuming and require manual sampling and equipped laboratories. Although several technologies have been proposed in recent years to either perform such tests in situ or reduce the experiment time required, several hours are still required even in the best cases. Portable devices, in addition, typically require a constant supply of consumables and electrical power and have difficulty supplying power in environmental settings without batteries or solar power.

A low-cost, low-maintenance and robust method to remotely monitor FIB such as E. coli and enterococci would provide a cost-effective and proactive approach to protecting people from illness and death related to the ingestion of contaminated water. By taking advantage of the fluorescence properties of certain substances, fluorescence sensors can provide a near-instantaneous quantification of several critical water-quality parameters. Recent studies have shown strong correlations between the fluorescence signal at a specific wavelength and the amount of FIB in water samples. An E. coli excitation wavelength intensity of $280 \mathrm{~nm}$ and emission wavelength intensity of $360 \mathrm{~nm}$ provide reasonable indications of $E$. coli in poor-sanitation waters. Although promising, these findings are currently not sufficient to develop a real-time FIB monitoring system, due to issues such as selectivity as there is evidence of other substances, other than FIB, fluorescing at the same wavelengths.

As such, we conclude by suggesting that a real-time, in situ FIB monitoring tool could be achieved by combining a reagentless fluorescence sensor targeting FIB-related wavelengths, with compensation algorithms to improve its robustness against interferences, and a second, accurate verification sensor, activated only when the fluorescence sensor is triggered, to ensure that FIB was actually the cause of detection rather than other confounding factors. The development of such a hybrid, real-time in situ FIB monitoring tool would boost the effectiveness of water quality management, leading to increased proactivity and preparedness to faecal contamination events.

Author Contributions: Literature collection: K.L.O.; Writing-Original Draft Preparation and Review and Editing: K.L.O., E.B. and R.A.S. All authors have read and agreed to the published version of the manuscript.

Funding: The authors thank Griffith School of Engineering and Built Environment, Gold Coast Campus, Griffith University, Parklands Drive, Southport, QLD 4222, Australia for their financial support.

Conflicts of Interest: The authors declare no conflict of interest. 


\section{Appendix A}

Table A1. Existing water quality preparation-type and measurement-type detection applications for E. coli and enterococci.

\begin{tabular}{|c|c|c|c|}
\hline Method & Features & Strengths & Barriers \\
\hline \multicolumn{4}{|c|}{ Preparation-Type Methods } \\
\hline $\begin{array}{c}\text { Membrane-filtration assays } \\
{[7,8,22,26-34,101]}\end{array}$ & $\begin{array}{l}\text { Widely used standard reference methods to identify } \\
\text { bacteria, virus, and organisms. Membrane filtration verifies, } \\
\text { compares, and references water tests by isolating and } \\
\text { eliminating discrete microbiological colonies for multiple } \\
\text { samples and volumes. }\end{array}$ & $\begin{array}{ll}\text { - } & \text { Large number of samples } \\
\text { and volumes }\end{array}$ & $\begin{array}{ll}\text { - } & \text { Risk of contamination } \\
- & \text { Consumables costs are high } \\
\text { - } & \text { Not in situ or automated } \\
\text { - } & \text { Time consuming } \\
\text { - } & \text { Results between } 18 \text { and } 24 \mathrm{~h} \\
\text { - } & \text { Non-reliable results for } \\
\text { - } & \text { turbid waters } \\
& \text { Low sensitivity }\end{array}$ \\
\hline $\begin{array}{c}\text { Culture-based assays } \\
{[22,32,35-48,51,99]}\end{array}$ & $\begin{array}{l}\text { Culture-based assays methods follow culturing, incubation, } \\
\text { and then measurement. These are simple and inexpensive } \\
\text { processes that are widely used quantification tools to } \\
\text { enumerate viral, bacterial, and protozoan pathogens. These } \\
\text { verify legally accepted limits of water contamination, track } \\
\text { specific markers, and compare results from other } \\
\text { monitoring results; and are useful in automated lab-in-vial } \\
\text { tools. }\end{array}$ & $\begin{array}{ll}\text { - } & \text { Widely used verification } \\
\text { - } & \text { methods used by authorities } \\
\text { - } & \text { Reagents used are not costly } \\
& \text { Accurate; high sensitivity with } \\
\text { appropriate media } \\
\text { - } & \text { Assesses living } \\
\text { (culturable) bacteria } \\
\text { - } & \text { Quantitative } \\
\text { - } & \text { Reproducible procedures }\end{array}$ & 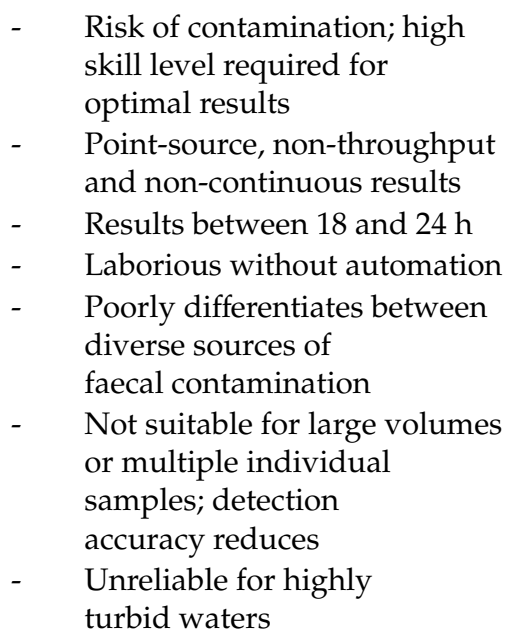 \\
\hline
\end{tabular}


Table A1. Cont.

\begin{tabular}{|c|c|c|c|}
\hline Method & Features & Strengths & Barriers \\
\hline \multicolumn{4}{|c|}{ Preparation-Type Methods } \\
\hline $\begin{array}{l}\text { Polymerase chain reaction } \\
\text { assays } \\
\begin{array}{c}{[7,22,29,30,36,37,45-47,49-56,} \\
82,135]\end{array}\end{array}$ & $\begin{array}{l}\text { Polymerase chain reaction assays amplify microorganisms } \\
\text { grown in culture for identification and involve three typical } \\
\text { steps of production, which requires high temperatures } \\
\text { under laboratory conditions. Polymerase chain reaction } \\
\text { assays are used with filtration and culture-based methods; } \\
\text { the production is typically analysed by sequencing, gel } \\
\text { electrophoresis, or cloned into a plasmid. }\end{array}$ & $\begin{array}{ll}\text { - } & \text { Amplification of indicators } \\
- & \text { Consistent identifications with } \\
\text { high sensitivity } \\
\text { - } & \text { Efficient and cost-effective } \\
- & \text { High accuracy } \\
\text { Rapid results, qPCR results } \\
\text { returned in a few hours } \\
\text { - } & \begin{array}{l}\text { High numbers of samples } \\
\text { processed at one time }\end{array} \\
\text { - } & \text { High true positive } \\
\text { response rates }\end{array}$ & $\begin{array}{ll}\text { - } & \begin{array}{l}\text { Typically requires } \\
\text { grab sampling }\end{array} \\
\text { - } & \text { In-laboratory results differ } \\
\text { depending on quality controls } \\
\text { - } \quad \text { Risk of contamination } \\
\text { - } \quad \text { Unable to distinguish live } \\
\text { from dead cells } \\
\text { - } \quad \text { Expertise required for } \\
\text { sophisticated procedures } \\
\text { - } \quad \text { High cost equipment } \\
\text { in laboratory } \\
\text { Costs of consumables are high } \\
\text { in many countries } \\
\text { - Not in situ, real-time, or } \\
\text { continuous results }\end{array}$ \\
\hline $\begin{array}{l}\text { DNA-probe assays } \\
{[29,36,46,57-61,136]}\end{array}$ & $\begin{array}{l}\text { Typically used in conjunction with labelling techniques and } \\
\text { act in suspensions as reagents. DNA probe assays directly } \\
\text { detect targeted organisms through the stretches of } \\
\text { single-stranded DNA opposing complementary structures } \\
\text { and or hybridisation between targeted sequences. }\end{array}$ & 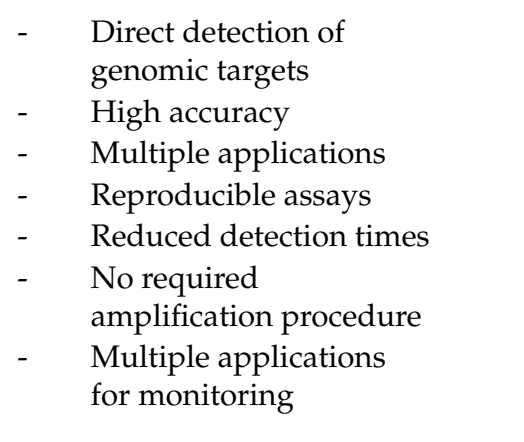 & $\begin{array}{ll}\text { - } & \text { Specialised equipment } \\
\text { and setup } \\
\text { - } & \begin{array}{l}\text { Expensive to obtain material } \\
\text { and maintain detection devices }\end{array} \\
\text { - } & \text { Multiple processes involving } \\
\text { assay production, culturing, } \\
\text { or filtration } \\
\text { - } \quad \text { Not in situ } \\
\text { - } \quad \text { Not-real-time and } \\
\text { not-continuous results } \\
\text { Risk of bio leakage }\end{array}$ \\
\hline
\end{tabular}


Table A1. Cont.

\begin{tabular}{|c|c|c|c|}
\hline Method & Features & Strengths & Barriers \\
\hline \multicolumn{4}{|c|}{ Measurement-Type Methods } \\
\hline $\begin{array}{l}\text { Absorption spectroscopy } \\
\text { measurements } \\
{[8,29,62-68,72,130,137,138]}\end{array}$ & $\begin{array}{l}\text { Absorption spectroscopy measures the absorption of light } \\
\text { by an unknown substance or sample generally performed } \\
\text { on molecules dissolved in transparent solvents or aqueous } \\
\text { buffers. Samples are illuminated with electromagnetic rays } \\
\text { of determinant wavelength depending on the choice; these } \\
\text { can include visible, ultraviolet, or the lower infrared } \\
\text { spectrum and then the absorbance of the sample is used to } \\
\text { calculate the concentration. }\end{array}$ & $\begin{array}{ll}- & \text { Reliable } \\
- & \text { Clearly-defined } \\
\text { - } & \text { spectral ranges } \\
& \text { Quantitative and } \\
\text { qualitative measurements } \\
\text { - } & \text { Accurate for targeted items; } \\
& \text { high sensitivity and specificity } \\
- & \text { Determines concentration of } \\
& \text { target in samples } \\
- & \text { Rapid results } \\
- & \text { Can make multiple detections }\end{array}$ & 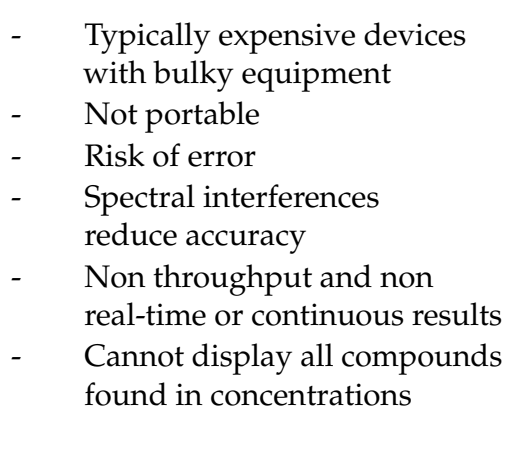 \\
\hline $\begin{array}{c}\text { Fluorescence } \\
{[8,23,29,34,36,38,60,62,67-79,82,} \\
111,113,121,130,139-142]\end{array}$ & $\begin{array}{l}\text { Fluorescence results from released energy in the form of } \\
\text { light, when fluorophores are excited by a high-energy light } \\
\text { source. }\end{array}$ & $\begin{array}{ll}- & \text { Cost-efficient approach } \\
- & \text { Simple detection methods } \\
- & \text { Reliable measurements } \\
- & \text { Rapid results } \\
- & \text { In situ through modern tools } \\
- & \text { Widely used by monitoring } \\
& \text { methods for } \\
\text { final measurements }\end{array}$ & $\begin{array}{ll}\text { - } & \text { Optical interferences } \\
& \text { reduce accuracy } \\
\text { - } & \text { Equipment can be costly } \\
\text { - } \quad \text { Some methods require } \\
\text { substantial capital costs } \\
\text { and expertise }\end{array}$ \\
\hline
\end{tabular}


Table A1. Cont.

\begin{tabular}{|c|c|c|c|}
\hline Method & Features & Strengths & Barriers \\
\hline \multicolumn{4}{|c|}{ Measurement-Type Methods } \\
\hline $\begin{array}{c}\text { Flow cytometry } \\
{[32,36,68,80-84,86]}\end{array}$ & $\begin{array}{l}\text { Flow cytometry determines individual cells, } \\
\text { microorganism's (bacteria) within complex matrices, } \\
\text { following cell staining (or constituents) with fluorescent } \\
\text { tags. Typically, test samples are injected into a liquid, } \\
\text { placed into the flow cytometry device then injected into } \\
\text { flow streams, which subsequently pass through the } \\
\text { flow-sensing area of the instrument for fluorescence-based } \\
\text { detection systems to measure the size, shape, number, } \\
\text { and concentration of the individual particles. }\end{array}$ & 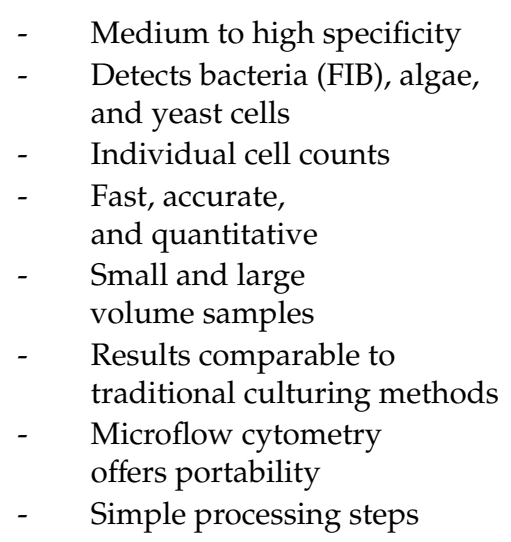 & $\begin{array}{ll}\text { - } & \text { Typically } \\
\text { expensive equipment } \\
\text { - } \quad \text { Expensive reagents used when } \\
\text { labelling is required } \\
\text { - } \quad \begin{array}{l}\text { Manual processing, grab } \\
\text { samples, preparation steps, } \\
\text { prior labelling of organisms }\end{array} \\
\text { - } \quad \text { Limited on-site availability } \\
\text { - } \quad \text { Not real-time, } \\
\text { non-continuous detection } \\
\text { - } \begin{array}{l}\text { Detections at low } \\
\text { concentration unreliable }\end{array} \\
\text { - } \quad \text { Regular maintenance required }\end{array}$ \\
\hline $\begin{array}{c}\text { Biosensors } \\
{[3,22,29,30,59,82,85-91,96,143-} \\
145]\end{array}$ & $\begin{array}{l}\text { Biosensors exploit biological reactions of proteins, cells, } \\
\text { antibodies, enzymes, receptors, nucleic acid, or } \\
\text { components, and detections are usually through a } \\
\text { physiochemical transducer integrated into electrical } \\
\text { interfaces, which converts a substance concentration into an } \\
\text { electrical signal. Some biosensors do not require sample } \\
\text { preconcentration or pre-enrichment procedures, and results } \\
\text { are comparable to conventional FIB detection methods. }\end{array}$ & $\begin{array}{ll}- & \text { Multiple applications } \\
- & \text { Field monitoring } \\
- & \text { Miniaturised } \\
- & \text { High sensitivity } \\
\text { - } & \text { Rapid detections } \\
- & \text { Typically simple } \\
& \text { preconcentration } \\
\text { procedures/processes } \\
\text { for samples } \\
\text { - } \quad \text { Reduced assay time } \\
\text { High true positive } \\
\text { response rates }\end{array}$ & $\begin{array}{ll}\text { - } & \text { Not real-time or } \\
\text { continuous results } \\
\text { - } \quad \text { Not possible remotely as } \\
\text { physical sampling is required } \\
\text { because most biosensors } \\
\text { require preprocessing with a } \\
\text { manual step or filtration } \\
\text { - } \quad \text { Sensitive to environment } \\
\text { - } \quad \text { Regular maintenance and } \\
\text { high cost } \\
\text { - }\end{array}$ \\
\hline
\end{tabular}


Table A1. Cont.

\begin{tabular}{|c|c|c|c|}
\hline Method & Features & Strengths & Barriers \\
\hline \multicolumn{4}{|c|}{ Measurement-Type Methods } \\
\hline $\begin{array}{c}\text { Lateral flow assays } \\
{[79,87,88,92-95]}\end{array}$ & $\begin{array}{l}\text { Lateral flow assays detect genetic markers of organisms; in } \\
\text { a typical layout, samples are placed in the chamber and } \\
\text { moved horizontally along the strip passing different zones } \\
\text { slowly. The analyte is typically an amplified } \\
\text { double-stranded nucleic acid sequence specific for the } \\
\text { organism with two different tags and recognition is made } \\
\text { through binding to its tag-specific antibody; or, reliant on } \\
\text { the hybridisation of target DNA. }\end{array}$ & $\begin{array}{ll}- & \text { Label free detection } \\
- & \text { Minimum sample volume } \\
- & \text { Fast operation } \\
- & \text { Accurate results } \\
- & \text { Detects various } \\
\text { - } & \text { genetic markers } \\
\text { - } & \text { Portable detection } \\
& \text { Simple detection mechanism } \\
\text { - } & \text { Qualitative } \\
& \text { and semiquantitative }\end{array}$ & $\begin{array}{l}\text { - Samples must move } \\
\text { horizontally along the strip } \\
\text { passing different zones slowly } \\
\text { to avoid innacuracy } \\
\text { - } \quad \text { Requires personnel } \\
\text { - } \text { Often not reusable and } \\
\text { non-continuous results } \\
\text { - Typically unable to distinguish } \\
\text { between viable and } \\
\text { non-viable cells } \\
\text { Low bacteria numbers can } \\
\text { require an enrichment step, } \\
\text { not always possible when } \\
\text { testing is in the field }\end{array}$ \\
\hline $\begin{array}{l}\text { Adenosine triphosphate } \\
\text { bioluminescence assays } \\
{[20,31,36,41,85,87,97,98]}\end{array}$ & $\begin{array}{l}\text { The ATP bioluminescence typically uses luciferase enzymes } \\
\text { and luciferin substrates to produce bioluminescence } \\
\text { determined and quantified through particular sensors. } \\
\text { Results are detected in the micromolar range through } \\
\text { multiple device platforms, but typically chromatography, } \\
\text { fluorescence, or immobilised luciferase sensors. }\end{array}$ & $\begin{array}{ll}\text { - } & \text { Reliable detections } \\
\text { - } & \text { Marker for microbial activity } \\
\text { - } & \text { Measures all active living cells } \\
\text { - } & \text { and organisms } \\
\text { - } & \text { Simple procedures assays } \\
\text { - } & \text { Quantitative results } \\
\text { - } & \text { Numerous testing applications } \\
& \text { Accurate calculations for } \\
\text { - } & \text { Simple concentration } \\
& \text { Simple processes }\end{array}$ & $\begin{array}{ll}\text { - } & \text { Costly equipment } \\
\text { and consumables } \\
\text { - } & \text { Personnel expertise required } \\
\text { - } & \text { Grab sampling, lengthy assays, } \\
\text { and sample preprocessing } \\
\text { - } \quad \text { Sensitive to illumination } \\
\text { - } \quad \text { Results not converted to } \\
\text { cell count } \\
\text { - Does not consistently } \\
\text { distinguish between viable } \\
\text { and non-viable cells } \\
\text { Less specific and sensitive } \\
\text { than regular } \\
\text { culture-based methods }\end{array}$ \\
\hline
\end{tabular}


Table A1. Cont.

\begin{tabular}{|c|c|c|c|}
\hline Method & Features & Strengths & Barriers \\
\hline \multicolumn{4}{|c|}{ Measurement-Type Methods } \\
\hline $\begin{array}{c}\text { Enzyme activity assays } \\
{[7,22,26,28,42-44,77,82,99-103,} \\
144-150]\end{array}$ & $\begin{array}{l}\text { The assays use enzyme chemistry and are used within } \\
\text { biosensors and find results through fluorescence. } \\
\text { Additionally, used in portable field kits, automated } \\
\text { instruments, and traditional laboratory techniques. }\end{array}$ & $\begin{array}{ll}- & \text { Accurate results } \\
- & \text { Used in many applications } \\
- & \text { Simple assessments } \\
\text { - } & \text { and processes } \\
- & \text { Reliable results } \\
- & \text { Selective markers } \\
- & \text { Rapid warnings for sewage } \\
& \text { contamination in waters }\end{array}$ & $\begin{array}{ll}\text { - } & \begin{array}{l}\text { Typically } \\
\text { expensive equipment }\end{array} \\
\text { - } & \begin{array}{l}\text { Reliant on enzymatic reactions } \\
\text { of the target, a medium, } \\
\text { and fluorogenic product }\end{array} \\
\text { - } \quad \text { Lengthy test procedures } \\
\text { - } \quad \begin{array}{l}\text { Tests requires experienced } \\
\text { personnel/laboratory operators }\end{array} \\
\text { - } \quad \text { Not real-time or continuous } \\
\text { - False positives occur when } \\
\text { coliform bacteria are present at } \\
\text { high concentrations, } \\
\text { and results are disturbed by } \\
\text { other bacteria }\end{array}$ \\
\hline $\begin{array}{l}\text { Automated in situ biosensors } \\
\text { using laboratory fluorescence } \\
\text { measurement } \\
{[19,59,104-106]}\end{array}$ & $\begin{array}{l}\text { It applies specific bioreagents to samples and following } \\
\text { incubation, measurements are made through fluorescence } \\
\text { or absorbance. }\end{array}$ & 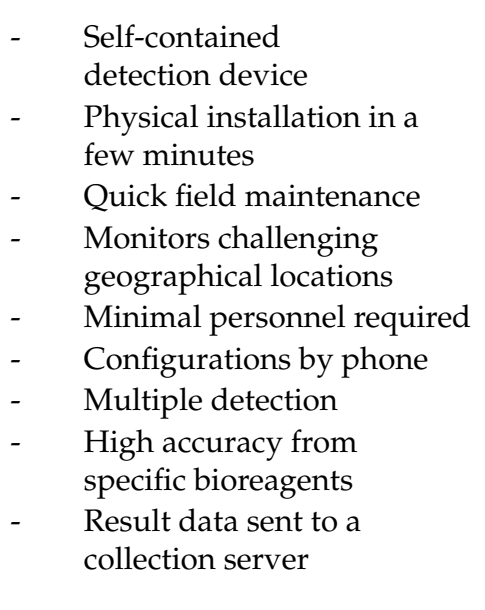 & $\begin{array}{ll}\text { - } & \begin{array}{l}\text { Typically expensive devices } \\
\text { and equipment }\end{array} \\
\text { - } & \text { Required regular maintenance } \\
\text { - } & \begin{array}{l}\text { Detection influenced } \\
\text { by turbidity }\end{array} \\
\text { - } \quad \begin{array}{l}\text { Data collection unreliable } \\
\text { when affected by unknown }\end{array} \\
\text { outside influence } \\
\text { - } \quad \text { False positives develop in salt } \\
\text { waters and require } \\
\text { prior adjustment } \\
\text { Non-throughput testing and } \\
\text { not real-time or continuous } \\
\text { - } \quad \text { Risk of bioreceptor leakages } \\
\text { - Limited transducer lifetime }\end{array}$ \\
\hline
\end{tabular}


Table A1. Cont.

\begin{tabular}{|c|c|c|c|}
\hline Method & Features & Strengths & Barriers \\
\hline \multicolumn{4}{|c|}{ Measurement-Type Methods } \\
\hline $\begin{array}{c}\text { Reagentless and portable } \\
\text { fluorescence spectroscopy } \\
\text { measurements } \\
{[8,23,34,73,75,76,111,112,130]}\end{array}$ & $\begin{array}{l}\text { Portable fluorescence spectroscopy devices can be } \\
\text { incorporated into floating buoys or mobile sensors; these } \\
\text { use fluorescence intensities of substances or organisms, } \\
\text { producing a fluorescence signal at specific excitation and } \\
\text { emission wavelengths to monitor water quality. }\end{array}$ & $\begin{array}{ll}\text { - } & \text { Low maintenance costs; } \\
& \text { low costs } \\
\text { - } & \text { Available under } \\
& \text { multiple conditions } \\
- & \text { No grab sampling required } \\
\text { - } & \text { No reagents required and } \\
& \text { minimal processing } \\
- & \text { Reproducibility } \\
- & \text { Rapid and continuous results } \\
- & \text { High accuracy } \\
-\quad & \text { In situ, portable, } \\
& \text { and miniaturisable }\end{array}$ & $\begin{array}{ll}\text { - } & \text { Regular maintenance to } \\
& \text { preserve the } \\
\text { optical components } \\
\text { - } & \text { Sensitive to illumination } \\
\text { - } & \text { Questionable robustness of } \\
\text { - } & \text { physical sensor } \\
\text { - } & \text { Sensitive to environment } \\
\text { - } & \text { Dalse positives occur } \\
\text { - } & \text { Limited specific wavelength } \\
& \text { transducer life }\end{array}$ \\
\hline
\end{tabular}




\section{References}

1. Soller, J.A.; Schoen, M.E.; Bartrand, T.; Ravenscroft, J.E.; Ashbolt, N.J. Estimated human health risks from exposure to recreational waters impacted by human and non-human sources of faecal contamination. Water Res. 2010, 44, 4674-4691. [CrossRef] [PubMed]

2. Bourke, K. Gold Coast City Recreational Waters: Methods to promote healthy swimming. In Proceedings of the Acting Senior Environmental Health Officer; Gold Coast City Council: Gold Coast, Australia, 2012; pp. 1-24.

3. Kumar, N.; Hu, Y.; Singh, S.; Mizaikoff, B. Emerging biosensor platforms for the assessment of water-borne pathogens. Analyst 2018, 143, 359-373. [CrossRef] [PubMed]

4. Bertone, E.; Purandare, J.; Durand, B. Spatiotemporal prediction of Escherichia coli and Enterococci for the Commonwealth Games triathlon event using Bayesian Networks. Mar. Pollut. Bull. 2019, 146, 11-21. [CrossRef] [PubMed]

5. Bulycheva, E.V.; Korotkova, E.I.; Voronova, O.A.; Kustova, A.A.; Petrova, E.V. Fluorescence Analysis of E. coli Bacteria in Water. Procedia Chem. 2014, 10, 179-183. [CrossRef]

6. Makvana, S.; Krilov, L.R. Escherichia coli infections. Pediatr. Rev. 2015, 36, 167-171. [CrossRef]

7. Chapman, J.; Anastasi, A.; Power, A.; Chandra, S.; Voss, L.; Rajapaksha, P.; Cosford, S. Detection Methods for Faecal Contamination Events: The Gap for Australia. Water e-J. Online J. Aust. Water Assoc. 2016, 1, 1-6. [CrossRef]

8. Sharpe, T.J. Assessing a Fluorescence Spectroscopy Method for In-Situ Microbial Drinking Water Quality. Master's Thesis, Portland State University, Portland, OR, USA, 2017.

9. Weiskerger, C.J.; Whitman, R.L. Monitoring E. coli in a changing beachscape. Sci. Total Environ. 2018, 619-620, 1236-1246. [CrossRef]

10. Lee, D.S.; Lee, S.J.; Choe, H.S.; Giacobbe, D.R. Community-Acquired Urinary Tract Infection by Escherichia coli in the Era of Antibiotic Resistance. Biomed. Res. Int. 2018, 2018, 1-14. [CrossRef]

11. Bertone, E.; Kozak, S.; Roiko, A. Understanding and Modeling the Occurrence of E. coli Blooms in Drinking Water Reservoirs. Water Resour. Res. 2019, 55, 10518-10526. [CrossRef]

12. Byappanahalli, M.N.; Nevers, M.B.; Korajkic, A.; Staley, Z.R.; Harwood, V.J. Enterococci in the Environment. Microbiol. Mol. Biol. Rev. 2012, 76, 685-706. [CrossRef]

13. Gilmore, M.S.; Clewell, D.B.; Ike, Y.; Shankar, N. Enterococci from Commensals to Leading Causes of Drug Resistant Infection; Gilmore, M.S., Clewell, D.B., Ike, Y., Shankar, N., Eds.; Massachusetts Eye and Ear Infirmary Boston: Boston, MA, USA, 2014.

14. Australian Commission on Safety and Quality in Health Care (ACSQHC). AURA 2016: First Australian Report on Antimicrobial Use and Resistance in Human Health-Summary Report; ACSQHC: Sydney, Australia, 2016.

15. Scott, T.M.; Rose, J.B.; Jenkins, T.M.; Farrah, S.R.; Lukasik, J. Microbial source tracking: Current methodology and future directions. Appl. Environ. Microbiol. 2002, 68, 5796-5803. [CrossRef] [PubMed]

16. Yuan, J. Evaluation of Different Indicator Microorganism Enumeration Protocols for Water Quality Monitoring. Master's Thesis, Auburn University, Auburn, AL, USA, 2016.

17. Healthy Waterways. Healthy Waterplay: Monitoring Recreational Water Waterways in South East Queensland; Healthy Waterways: Brisbane, Australia, 2013.

18. City of Gold Coast. Recreational Water Quality. Available online: https://www.goldcoast.qld.gov.au/ environment/recreational-water-quality-20260.html (accessed on 4 August 2020).

19. Angelescu, D.E.; Huynh, V.; Hausot, A.; Yalkin, G.; Plet, V.; Mouchel, J.-M.; Guérin-Rechdaoui, S.; Azimi, S.; Rocher, V. Autonomous system for rapid field quantification of Escherichia coli in surface waters. J. Appl. Microbiol. 2018. [CrossRef]

20. Chollet, R.; Ribault, S. Use of ATP Bioluminescence for Rapid Detection and Enumeration of Contaminants: The Milliflex Rapid Microbiology Detection and Enumeration System. In Bioluminescence-Recent Advances in Oceanic Measurements and Laboratory Applications; Lapota, D., Ed.; IntechOpen: London, UK, 2012; pp. 99-118. ISBN 978-953-307-940-0.

21. City of Gold Coast. Waterways Monitoring. Available online: https://www.goldcoast.qld.gov.au/ environment/waterways-monitoring-3963.html (accessed on 4 August 2020).

22. Price, R.G.; Wildeboer, D. Chapter 7: E. coli as an Indicator of Contamination and Health Risk in Environmental Waters. In Escherichia coli-Recent Advances on Physiology, Pathogenesis and Biotechnological Applications; Samie, A., Ed.; IntechOpen: London, UK, 2017; pp. 125-139. ISBN 978-953-51-3330-8. 
23. Sorensen, J.P.R.; Baker, A.; Cumberland, S.A.; Lapworth, D.J.; MacDonald, A.M.; Pedley, S.; Taylor, R.G.; Ward, J.S.T. Real-time detection of faecally contaminated drinking water with tryptophan-like fluorescence: Defining threshold values. Sci. Total Environ. 2018, 622-623, 1250-1257. [CrossRef] [PubMed]

24. Moher, D.; Liberati, A.; Tetzlaff, J.; Altman, D.G.; Altman, D.; Antes, G.; Atkins, D.; Barbour, V.; Barrowman, N.; Berlin, J.A.; et al. Preferred reporting items for systematic reviews and meta-analyses: The PRISMA statement. PLoS Med. 2009, 6, e1000097. [CrossRef] [PubMed]

25. Polanin, J.R.; Pigott, T.D.; Espelage, D.L.; Grotpeter, J.K. Best practice guidelines for abstract screening large-evidence systematic reviews and meta-analyses. Res. Synth. Methods 2019, 10, 330-342. [CrossRef]

26. United States Environmental Protection Agency (EPA). Method 1604: Total Coliforms and Escherichia coli in Water by Membrane Filtration Using a Simultaneous Detection Technique (MI Medium); United States Environmental Protection Agency Office: Washington, DC, USA, 2002.

27. United States Environmental Protection Agency (EPA). Method 1603: Escherichia coli (E. coli) in Water by Membrane Filtration Using Modified Membrane-Thermotolerant Escherichia coli Agar (Modified mTEC); United States Environmental Protection Agency Office: Washington, DC, USA, 2014.

28. United States Environmental Protection Agency (EPA). Method 1600: Enterococci in Water by Membrane Filtration Using Membrane-Enterococcus Indoxyl-Beta-D-Glucoside Agar (mEI); United States Environmental Protection Agency (EPA): Washington, DC, USA, 2009.

29. Zulkifli, S.N.; Rahim, H.A.; Lau, W.-J. Detection of contaminants in water supply: A review on state-of-the-art monitoring technologies and their applications. Sens. Actuators B Chem. 2018, 255, 2657-2689. [CrossRef] [PubMed]

30. Nurliyana, M.R.; Sahdan, M.Z.; Wibowo, K.M.; Muslihati, A.; Saim, H.; Ahmad, S.A.; Sari, Y.; Mansor, Z. The Detection Method of Escherichia coli in Water Resources: A Review. J. Phys. Conf. Ser. 2018, 995, 1-11. [CrossRef]

31. Ngamsom, B.; Fourie, L.; Tarn, M.D.; Kumar, S.; Moodley, K.; Land, K.; Pamme, N. Rapid detection of E. coli O157:H7 by IFAST and ATP bioluminescence assay for water analysis. In Proceedings of the The 20th International Conference of Miniaturized Systems for Chemistry and Life Sciences (MicroTAS 2016), Dublin, Ireland, 9-13 October 2016; ResearchGate: Dublin, Ireland, 2016; pp. 63-64.

32. Guo, T.; Wei, Y.; Xu, C.; Watts, B.R.; Zhang, Z.; Fang, Q.; Zhang, H.; Selvaganapathy, P.R.; Deen, M.J. Counting of escherichia coli by a microflow cytometer based on a photonic-microfluidic integrated device. Electrophoresis 2015, 36, 298-304. [CrossRef]

33. Guo, T. Optical System towards In-line Monitoring of Bacteria in Drinking Water. Ph.D. Thesis, Mcmaster University, Hamilton, ON, Canada, 2016.

34. Cumberland, S.; Bridgeman, J.; Baker, A.; Sterling, M.; Ward, D. Fluorescence spectroscopy as a tool for determining microbial quality in potable water applications. Environ. Technol. 2012, 33, 687-693. [CrossRef]

35. Tan, B.; Ng, C.; Nshimyimana, J.P.; Loh, L.L.; Gin, K.Y.H.; Thompson, J.R. Next-generation sequencing (NGS) for assessment of microbial water quality: Current progress, challenges, and future opportunities. Front. Microbiol. 2015, 6, 1-20. [CrossRef]

36. Rajapaksha, P.; Elbourne, A.; Gangadoo, S.; Brown, R.; Cozzolino, D.; Chapman, J. A review of methods for the detection of pathogenic microorganisms. Analyst 2019, 144, 396-411. [CrossRef]

37. Girones, R.; Ferrús, M.A.; Alonso, J.L.; Rodriguez-Manzano, J.; Calgua, B.; de Abreu Corrêa, A.; Hundesa, A.; Carratala, A.; Bofill-Mas, S. Molecular detection of pathogens in water-The pros and cons of molecular techniques. Water Res. 2010, 44, 4325-4339. [CrossRef] [PubMed]

38. Veolia Water Solutions \& Technologies TECTA: Solutions for Automated Microbiology. Available online: http://technomaps.veoliawatertechnologies.com/processes/lib/2548,TECTA-Brochure-EN.pdf (accessed on 19 June 2019).

39. McLain, J.E.; Cytryn, E.; Durso, L.M.; Young, S. Culture-based Methods for Detection of Antibiotic Resistance in Agroecosystems: Advantages, Challenges, and Gaps in Knowledge. J. Environ. Qual. 2016, 45, 432-440. [CrossRef] [PubMed]

40. Napier, M.D.; Poole, C.; Stewart, J.R.; Weber, D.J.; Glassmeyer, S.T.; Kolpin, D.W.; Furlong, E.T.; Dufour, A.P.; Wade, T.J. Exposure to Human-Associated Chemical Markers of Fecal Contamination and Self-Reported Illness among Swimmers at Recreational Beaches. Environ. Sci. Technol. 2018, 52, 7513-7523. [CrossRef]

41. Vang, Ó.K. ATP Measurements for Monitoring Microbial Drinking Water Quality. Ph.D. Thesis, Technical University of Denmark, Lyngby, Denmark, 2013. 
42. Burnet, J.B.; Dinh, Q.T.; Imbeault, S.; Servais, P.; Dorner, S.; Prévost, M. Autonomous online measurement of $\beta$-D-glucuronidase activity in surface water: Is it suitable for rapid E. coli monitoring? Water Res. 2019, 152, 241-250. [CrossRef] [PubMed]

43. Lebaron, P.; Henry, A.; Lepeuple, A.S.; Pena, G.; Servais, P. An operational method for the real-time monitoring of E. coli numbers in bathing waters. Mar. Pollut. Bull. 2005, 50, 652-659. [CrossRef]

44. Briciu-Burghina, C.; Heery, B.; Regan, F. Protocol for the recovery and detection of Escherichia coli in environmental water samples. Anal. Chim. Acta 2017, 964, 178-186. [CrossRef]

45. Saxena, T.; Kaushik, P.; Krishna Mohan, M. Prevalence of E. coli O157: H7 in water sources: An overview on associated diseases, outbreaks and detection methods. Diagn. Microbiol. Infect. Dis. 2015, 82, 249-264. [CrossRef]

46. Khan, A.S. Rapid Advances in Nucleic Acid Technologies for Detection and Diagnostics of Pathogens. J. Microbiol. Exp. 2014, 1, 56-61. [CrossRef]

47. Jiang, Y.S.; Riedel, T.E.; Popoola, J.A.; Morrow, B.R.; Cai, S.; Ellington, A.D.; Bhadra, S. Portable platform for rapid in-field identification of human fecal pollution in water. Water Res. 2018, 131, 186-195. [CrossRef]

48. Schang, C.; Henry, R.; Kolotelo, P.A.; Prosser, T.; Crosbie, N.; Grant, T.; Cottam, D.; O’Brien, P.; Coutts, S.; Deletic, A.; et al. Evaluation of techniques for measuring microbial hazards in bathing waters: A comparative study. PLOS ONE 2016, 11, e0155848. [CrossRef]

49. Ochman, H.; Gerber, A.S.; Hart, D.L. Genetic Applications of an Inverse Polymerase Chain Reaction. Genetics 1988, 120, 621-623.

50. Garibyan, L.; Avashia, N. Research Techniques Made Simple: Polymerase Chain Reaction (PCR). J. Investig. Dermatol. 2013, 133, e6. [CrossRef]

51. Mendes Silva, D.; Domingues, L. On the track for an efficient detection of Escherichia coli in water: A review on PCR-based methods. Ecotoxicol. Environ. Saf. 2015, 113, 400-411. [CrossRef] [PubMed]

52. Lam, J.T.; Lui, E.; Chau, S.; Kueh, C.S.W.; Yung, Y.K.; Yam, W.C. Evaluation of real-time PCR for quantitative detection of Escherichia coli in beach water. J. Water Health 2014, 12, 51-56. [CrossRef] [PubMed]

53. Frahm, E.; Obst, U. Application of the fluorogenic probe technique (TaqMan PCR) to the detection of Enterococcus spp. and Escherichia coli in water samples. J. Microbiol. Methods 2003, 52, 123-131. [CrossRef]

54. Walker, D.I.; McQuillan, J.; Taiwo, M.; Parks, R.; Stenton, C.A.; Morgan, H.; Mowlem, M.C.; Lees, D.N. A highly specific Escherichia coli qPCR and its comparison with existing methods for environmental waters. Water Res. 2017, 126, 101-110. [CrossRef]

55. Noble, R.T.; Weisberg, S.B. A review of technologies for rapid detection of bacteria in recreational waters. J. Water Health 2005, 3, 381-392. [CrossRef]

56. Xue, Y.; Wilkes, J.G.; Moskal, T.J.; Williams, A.J.; Cooper, W.M.; Nayak, R.; Rafii, F.; Buzatu, D.A. Development of a flow cytometry-based method for rapid detection of Escherichia coli and Shigella spp. using an oligonucleotide probe. PLoS ONE 2016, 11, e0150038. [CrossRef]

57. Monsur Ali, M.; Aguirre, S.D.; Lazim, H.; Li, Y. Fluorogenic DNAzyme probes as bacterial indicators. Angew. Chem. Int. Ed. 2011, 50, 3751-3754. [CrossRef]

58. Hashemi, E.; Forouzandeh, M. Designing a new biosensor "DNA ELISA" to detect Escherichia coli using genomic DNA and comparison of this method to PCR-ELISA. J. Enzyme Inhib. Med. Chem. 2018, 33, 722-725. [CrossRef] [PubMed]

59. Srivastava, K.R.; Awasthi, S.; Mishra, P.K.; Srivastava, P.K. Chapter 13. Biosensors/molecular tools for detection of waterborne pathogens. In Waterborne Pathogens; Elsevier: Amsterdam, The Netherlands, 2020; pp. 237-277. ISBN 9780128187838.

60. Juhna, T.; Birzniece, D.; Larsson, S.; Zulenkovs, D.; Sharipo, A.; Azevedo, N.F.; Ménard-Szczebara, F.; Castagnet, S.; Féliers, C.; Keevil, C.W. Detection of Escherichia coli in biofilms from pipe samples and coupons in drinking water distribution networks. Appl. Environ. Microbiol. 2007, 73, 7456-7464. [CrossRef] [PubMed]

61. Stender, H.; Broomer, A.J.; Oliveira, K.; Perry-O'keefe, H.; Hyldig-nielsen, J.J.; Sage, A.; Coull, J. Rapid Detection, Identification, and Enumeration of Escherichia coli Cells in Municipal Water by Chemiluminescent In Situ Hybridization. Appl. Environ. Microbiol. 2001, 67, 142-147. [CrossRef] [PubMed]

62. Blaen, P.J.; Khamis, K.; Lloyd, C.E.M.; Bradley, C.; Hannah, D.; Krause, S. Real-time monitoring of nutrients and dissolved organic matter in rivers: Capturing event dynamics, technological opportunities and future directions. Sci. Total Environ. 2016, 569-570, 647-660. [CrossRef] [PubMed] 
63. Schmid, F.-X. (University of B.G. Biological Macromolecules: UV-visible Spectrophotometry. Encycl. Life Sci. 2001, 1-4. [CrossRef]

64. Kiefer, J.; Ebel, N.; Schlücker, E.; Leipertz, A. Characterization of Escherichia coli suspensions using UV/Vis/NIR absorption spectroscopy. Anal. Methods 2010, 2, 123-128. [CrossRef]

65. De Caro, C.; Haller, C. UV/VIS Spectrophotometry_Fundamentals and Applications; Mettler-Toledo Publication No. ME-30256131: Greifensee, Switzerland, 2015.

66. Park, C.W.; Yoon, K.Y.; Byeon, J.H.; Kim, K.; Hwang, J. Development of rapid assessment method to determine bacterial viability based on ultraviolet and visible (UV-Vis) spectroscopy analysis including application to bioaerosols. Aerosol Air Qual. Res. 2012, 12, 395-404. [CrossRef]

67. Fan, C.; Hsiang, J.C.; Jablonski, A.E.; Dickson, R.M. All-optical fluorescence image recovery using modulated stimulated emission depletion. Chem. Sci. 2011, 2, 1080-1085. [CrossRef]

68. Bridgeman, J.; Baker, A.; Brown, D.; Boxall, J.B. Portable LED fluorescence instrumentation for the rapid assessment of potable water quality. Sci. Total Environ. 2015, 524-525, 338-346. [CrossRef]

69. The Molecular Probes Handbook: A Guide to Fluorescent Probes and Labeling Technologies. Introduction to Fluorescence Techniques; Invitrogen by ThermoFisher Scientific; ThermoFisher Scientific: Waltham, MA, USA, 2010.

70. PerkinElmer Ltd. An. Introduction to Fluorescence Spectroscopy; PerkinElmer Ltd.: Buckinghamshire, UK, 2011; ISBN 0080923348.

71. Simões, J.; Dong, T. Continuous and real-time detection of drinking-water pathogens with a low-cost fluorescent optofluidic sensor. Sensors 2018, 18, 2210. [CrossRef]

72. Carstea, E.M.; Bridgeman, J.; Baker, A.; Reynolds, D.M. Fluorescence spectroscopy for wastewater monitoring: A review. Water Res. 2016, 95, 205-219. [CrossRef] [PubMed]

73. Carstea, E.M.; Popa, C.L.; Baker, A.; Bridgeman, J. In situ fluorescence measurements of dissolved organic matter: A review. Sci. Total Environ. 2020, 699, 134361. [CrossRef]

74. Shields, R.C.; Kaspar, J.R.; Lee, K.; Underhill, S.A.M.; Burne, R.A. Fluorescence tools adapted for real-time monitoring of the behaviors of Streptococcus species. Appl. Environ. Microbiol. 2019, 1-41. [CrossRef] [PubMed]

75. Okache, J.; Haggett, B.; Maytum, R.; Mead, A.; Rawson, D.; Ajmal, T. Sensing fresh water contamination using fluorescence methods. In Proceedings of the 2015 IEEE SENSORS, Busan, Korea, 1-4 November 2015; IEEE: Busan, Korea, 2015; pp. 1-4.

76. Baker, A.; Cumberland, S.A.; Bradley, C.; Buckley, C.; Bridgeman, J. To what extent can portable fluorescence spectroscopy be used in the real-time assessment of microbial water quality? Sci. Total Environ. 2015, 532, 14-19. [CrossRef] [PubMed]

77. Bramburger, A.J.; Stephen Brown, R.; Haley, J.; Ridal, J.J. A new, automated rapid fluorometric method for the detection of Escherichia coli in recreational waters. J. Great Lakes Res. 2015, 41, 298-302. [CrossRef]

78. Oda, M.; Morita, M.; Unno, H.; Tanji, Y. Rapid detection of Escherichia coli O157: H7 by using green fluorescent protein-labeled PP01 bacteriophage. Appl. Environ. Microbiol. 2004, 70, 527-534. [CrossRef]

79. Ferrero, F.J.; Valledor, M.; Campo, J.C.; Marin, L.; Gutierrez-Del-Rio, I.; Fernandez, J.; Lombo, F.; Cobian, N.; Olmos, F.; Mendez, I. A Novel Handheld Fluorimeter for Rapid Detection of Escherichia coli in Drinking Water. IEEE Sens. J. 2016, 16, 5136-5144. [CrossRef]

80. Bio-Rad Laboratories Inc. Flow Cytometry Basics Guide; Bio-Rad Laboratories Inc.: Hercules, CA, USA, 2015; ISBN 9781107671812.

81. Helmi, K.; Barthod, F.; Méheut, G.; Henry, A.; Poty, F.; Laurent, F.; Charni-Ben-Tabassi, N. Methods for microbiological quality assessment in drinking water: A comparative study. J. Water Health 2015, 13.1, $34-41$. [CrossRef]

82. Tatari, K.; Corfitzen, C.B.; Albrechtsen, H.; Christensen, S.C.B. Sensors for Microbial Drinking Water Quality; Technical University of Denmark: Lyngby, Denmark, 2016.

83. Watts, B.R.; Zhang, Z.; Xu, C.Q.; Cao, X.; Lin, M. A photonic-microfluidic integrated device for reliable fluorescence detection and counting. Electrophoresis 2012, 33, 3236-3244. [CrossRef]

84. Cyto-Water Rapid, Flexible Water Analysis Creates Industry Stir; ICFO: Barcelona, Spain, 2018.

85. Woutersen, M.; Belkin, S.; Brouwer, B.; Van Wezel, A.P.; Heringa, M.B. Are luminescent bacteria suitable for online detection and monitoring of toxic compounds in drinking water and its sources? Anal. Bioanal. Chem. 2011, 400, 915-929. [CrossRef] 
86. Sherchan, S.P. Monitoring Microbial Water Quality via Online Sensors. Ph.D. Thesis, The University of Arizona, Tucson, AZ, USA, 2013.

87. Samendra, P.; Masaaki, K.; Charles, P.; Ian, L. Rapid Detection Technologies for Monitoring Microorganisms in Water. Biosens. J. 2014, 3, 1-8. [CrossRef]

88. Kumar, S.; Nehra, M.; Mehta, J.; Dilbaghi, N.; Marrazza, G.; Kaushik, A. Point-of-Care Strategies for Detection of Waterborne Pathogens. Sensors 2019, 19, 4476. [CrossRef] [PubMed]

89. Thakur, B.; Zhou, G.; Chang, J.; Pu, H.; Jin, B.; Sui, X.; Yuan, X.; Yang, C.H.; Magruder, M.; Chen, J. Rapid detection of single E. coli bacteria using a graphene-based field-effect transistor device. Biosens. Bioelectron. 2018, 110, 16-22. [CrossRef]

90. Gunda, N.S.K.; Dasgupta, S.; Mitra, S.K. DipTest: A litmus test for E. coli detection in water. PLoS ONE 2017, 12, 1-13. [CrossRef]

91. Park, T.S.; Yoon, J.Y. Smartphone detection of Escherichia coli from field water samples on paper microfluidics. IEEE Sens. J. 2015, 15, 1902-1907. [CrossRef]

92. Zhao, S.; Wang, S.; Zhang, S.; Liu, J.; Dong, Y. State of the art: Lateral flow assay (LFA) biosensor for on-site rapid detection. Chinese Chem. Lett. 2018, 29, 1567-1577. [CrossRef]

93. Posthuma-Trumpie, G.A.; Korf, J.; Van Amerongen, A. Lateral flow (immuno)assay: Its strengths, weaknesses, opportunities and threats. A literature survey. Anal. Bioanal. Chem. 2009, 393, 569-582. [CrossRef]

94. BlažkoVá, M.; Koets, M.; Wichers, J.H.; Van Amerongen, A.; Fukal, L.; Rauch, P. Nucleic acid lateral flow immunoassay for the detection of pathogenic bacteria from food. Czech. J. Food Sci. 2009, 27. [CrossRef]

95. Bubert, A.; Paiva, G.; Smith, T.; Bülte, M. Rapid and Simple Detection of E. coli 0157:H7 in Water Samples after Enrichment with Readycult ${ }^{\circledR}$; AWAA Poster; University of Giessen: Giessen, Gemany, 2003.

96. Liao, D.S.; Raveendran, J.; Golchi, S.; Docoslis, A. Fast and sensitive detection of bacteria from a water droplet by means of electric field effects and micro-Raman spectroscopy. Sens. Bio-Sens. Res. 2015, 6, 59-66. [CrossRef]

97. Lee, J.Y.; Deininger, R.A. Detection of E. coli in beach water within 1 hour using immunomagnetic separation and ATP bioluminescence. Luminescence 2004, 19, 31-36. [CrossRef]

98. Zimmer-Faust, A.G.; Thulsiraj, V.; Ferguson, D.; Jay, J.A. Performance and specificity of the covalently linked immunomagnetic separation-ATP method for rapid detection and enumeration of enterococci in coastal environments. Appl. Environ. Microbiol. 2014, 1-39. [CrossRef] [PubMed]

99. Heery, B.; Briciu-Burghina, C.; Zhang, D.; Duffy, G.; Brabazon, D.; O'Connor, N.; Regan, F. ColiSense, today's sample today: A rapid on-site detection of $\beta$-D-Glucuronidase activity in surface water as a surrogate for E. coli. Talanta 2016, 148, 75-83. [CrossRef] [PubMed]

100. Tryland, I.; Braathen, H.; Wennberg, A.C.; Eregno, F.; Beschorner, A.-L. Monitoring of $\beta$-D-galactosidase activity as a surrogate parameter for rapid detection of sewage contamination in urban recreational water. Water 2016, 8, 65. [CrossRef]

101. Bushon, R.N.; Brady, A.M.G.; Lindsey, B.D. Holding-time and method comparisons for the analysis of fecal-indicator bacteria in groundwater. Environ. Monit. Assess. 2015, 187, 1-11. [CrossRef] [PubMed]

102. Baudart, J.; Servais, P.; De Paoli, H.; Henry, A.; Lebaron, P. Rapid enumeration of Escherichia coli in marine bathing waters: Potential interference of nontarget bacteria. J. Appl. Microbiol. 2009, 107, $2054-2062$. [CrossRef] [PubMed]

103. Rochelet, M.; Solanas, S.; Betelli, L.; Chantemesse, B.; Vienney, F.; Hartmann, A. Rapid amperometric detection of Escherichia coli in wastewater by measuring $\beta$-D glucuronidase activity with disposable carbon sensors. Anal. Chim. Acta 2015, 892, 160-166. [CrossRef]

104. Huynh, V.; Hausot, A.; Angelescu, D.E. An autonomous field sensor for Total Coliform and E. coli monitoring at remote sites. In Proceedings of the OCEANS 2016 MTS/IEEE Monterey, Monterey, CA, USA, 19-23 September 2016; Huynh, V., Hausot, A., Angelescu, D.E., Eds.; IEEE: Monterey, CA, USA, 2016; pp. 1-5.

105. Fluidion ALERT LAB (Portable Analyzer): The Autonomous Microbiology Mobile Analysis Lab. Available online: http://fluidion.com/images/Documents/FLUIDION_ALERT_LAB_20180307_EN.pdf (accessed on 6 November 2018).

106. Fluidion ALERT System (In-Situ Analyzer): The Industry's First Fully-Automated In-Situ Microbiology Lab. Available online: http://fluidion.com/images/Documents/FLUIDION_ALERT_20180307_EN.pdf (accessed on 6 November 2018). 
107. Colifast AS Colifast Field Kit: Rapid Detection of Indicator Bacteria in Water. Available online: https: //colifast.no/wp-content/uploads/pdf/cmd_brochure.pdf (accessed on 19 July 2019).

108. Wildeboer, D.; Amirat, L.; Price, R.G.; Abuknesha, R.A. Rapid detection of Escherichia coli in water using a hand-held fluorescence detector. Water Res. 2010, 44, 2621-2628. [CrossRef]

109. Stojanović, M.; Apostolović, M.; Stojanović, D.; Milošević, Z.; Toplaović, A.; Lakušić, V.M.; Golubović, M. Understanding sensitivity, Specificity and predictive values. Vojnosanit. Pregl. 2014, 71, 1062-1065. [CrossRef]

110. Harwood, V.J.; Staley, C.; Badgley, B.D.; Borges, K.; Korajkic, A. Microbial source tracking markers for detection of fecal contamination in environmental waters: Relationships between pathogens and human health outcomes. FEMS Microbiol. Rev. 2014, 38, 1-40. [CrossRef]

111. Gaulier, G.; Staedler, D.; Sousa, G.; Bonacina, L.; Wolf, J.P. Real-time monitoring of bacterial and organic pollution in a water stream by fluorescence depletion spectroscopy. Appl. Phys. B Lasers Opt. 2017, 123, 2-6. [CrossRef]

112. Walck, M. Prompt and In Situ Diagnosis of Live/Dead Bacteria. Bachelor's Thesis, Texas A\&M University, College Station, TX, USA, 2016.

113. Carstea, E.M.; Baker, A.; Bieroza, M.; Reynolds, D. Continuous fluorescence excitation-emission matrix monitoring of river organic matter. Water Res. 2010, 44, 5356-5366. [CrossRef]

114. Wasswa, J.; Mladenov, N. Improved Temperature Compensation for In Situ Humic-Like and Tryptophan-Like Fluorescence Acquisition in Diverse Water Types. Environ. Eng. Sci. 2018, 35, 1-7. [CrossRef]

115. Sorensen, J.P.R.; Lapworth, D.J.; Marchant, B.P.; Nkhuwa, D.C.W.; Pedley, S.; Stuart, M.E.; Bell, R.A.; Chirwa, M.; Kabika, J.; Liemisa, M.; et al. In-situ tryptophan-like fluorescence: A real-time indicator of faecal contamination in drinking water supplies. Water Res. 2015, 81, 38-46. [CrossRef] [PubMed]

116. Sorensen, J.P.R.; Vivanco, A.; Ascott, M.J.; Gooddy, D.C.; Lapworth, D.J.; Read, D.S.; Rushworth, C.M.; Bucknall, J.; Herbert, K.; Karapanos, I.; et al. Online fluorescence spectroscopy for the real-time evaluation of the microbial quality of drinking water. Water Res. 2018, 137, 301-309. [CrossRef] [PubMed]

117. Henderson, R.K.; Baker, A.; Murphy, K.R.; Hambly, A.; Stuetz, R.M.; Khan, S.J. Fluorescence as a potential monitoring tool for recycled water systems: A review. Water Res. 2009, 43, 863-881. [CrossRef]

118. Chen, S.; Yu, Y.L.; Wang, J.H. Inner filter effect-based fluorescent sensing systems: A review. Anal. Chim. Acta 2018, 999, 13-26. [CrossRef]

119. De Oliveira, G.F.; Bertone, E.; Stewart, R.A.; Awad, J.; Holland, A.; O’Halloran, K.; Bird, S. Multi-parameter compensation method for accurate in situ fluorescent dissolved organic matter monitoring and properties characterization. Water 2018, 10, 1146. [CrossRef]

120. Government of Western Australia Department of Water. Surface Water Sampling Methods and Analysis-Technical Appendices: Standard Operating Procedures for Water Sampling-Methods and Analysis; Heald, D., Water Science Branch, Eds.; Government of Western Australia: Perth, Australia, 2009.

121. Khamis, K.; Sorensen, J.P.R.; Bradley, C.; Hannah, D.M.; Lapworth, D.J.; Stevens, R. In situ tryptophan-like fluorometers: Assessing turbidity and temperature effects for freshwater applications. Environ. Sci. Process. Impacts 2015, 17, 740-752. [CrossRef]

122. Bertone, E.; Burford, M.A.; Hamilton, D.P. Fluorescence probes for real-time remote cyanobacteria monitoring: A review of challenges and opportunities. Water Res. 2018, 141, 152-162. [CrossRef]

123. Baker, A.; Elliott, S.; Lead, J.R. Effects of filtration and $\mathrm{pH}$ perturbation on freshwater organic matter fluorescence. Chemosphere 2007, 67, 2035-2043. [CrossRef] [PubMed]

124. Bertone, E.; De Oliveira, G.F.; Stewart, R.; Halloran, K.O. Using compensated fluorescence probes data for proactive water treatment management. In Proceedings of the 13th International Conference on Hydroinformatics, Palermo, Italy, 1-6 July 2018; ResearchGate: London, UK, 2018; pp. 1-8.

125. Bharadwaj, R.; Sai, V.V.R.; Thakare, K.; Dhawangale, A.; Kundu, T.; Titus, S.; Verma, P.K.; Mukherji, S. Evanescent wave absorbance based fiber optic biosensor for label-free detection of $E$. coli at $280 \mathrm{~nm}$ wavelength. Biosens. Bioelectron. 2011, 26, 3367-3370. [CrossRef] [PubMed]

126. Mahmud, M.; Ejeian, F.; Azadi, S.; Myers, M.; Pejcic, B.; Abbasi, R.; Razmjou, A.; Asadnia, M. Recent progress in sensing nitrate, nitrite, phosphate, and ammonium in aquatic environment. ECSN 2020, 127492. [CrossRef]

127. ResearchGate. Available online: https://www.researchgate.net/post/Can_you_recommend_popular_ programs_for_deconvolution_which_are_used_by_analysts (accessed on 6 August 2020).

128. PeakFIT Automated Peak Seperation Analysis. Available online: http://www.sigmaplot.co.uk/products/ peakfit/peakfit.php (accessed on 6 August 2020). 
129. Sgroi, M.; Roccaro, P.; Korshin, G.V.; Greco, V.; Sciuto, S.; Anumol, T.; Snyder, S.A.; Vagliasindi, F.G.A. Use of fluorescence EEM to monitor the removal of emerging contaminants in full scale wastewater treatment plants. J. Hazard. Mater. 2017, 323, 367-376. [CrossRef]

130. Heibati, M.; Stedmon, C.A.; Stenroth, K.; Rauch, S.; Toljander, J.; Säve-Söderbergh, M.; Murphy, K.R. Assessment of drinking water quality at the tap using fluorescence spectroscopy. Water Res. 2017, 125, 1-10. [CrossRef]

131. Khamis, K.; Bradley, C.; Stevens, R.; Hannah, D.M. Continuous field estimation of dissolved organic carbon concentration and biochemical oxygen demand using dual-wavelength fluorescence, turbidity and temperature. Hydrol. Process. 2017, 31, 540-555. [CrossRef]

132. Watras, C.J.; Hanson, P.C.; Stacy, T.L.; Morrison, K.M.; Mather, J.; Hu, Y.H.; Milewski, P. A temperature compensation method for CDOM fluorescence sensors in freshwater. Limnol. Oceanogr. Methods 2011, 9 , 296-301. [CrossRef]

133. De Oliveira, G.F.; Bertone, E.; Stewart, R.A.; O’Halloran, K. Understanding and modelling fluorescent dissolved organic matter probe readings for improved coagulation performance in water treatment plants. In Proceedings of the 22nd International Congress on Modelling and Simulation, Hobart, Tasmania, Australia, 3-8 December 2017.

134. Hinkley, T.C.; Garing, S.; Singh, S.; Le Ny, A.L.M.; Nichols, K.P.; Peters, J.E.; Talbert, J.N.; Nugen, S.R. Reporter bacteriophage T7NLC utilizes a novel NanoLuc::CBM fusion for the ultrasensitive detection of Escherichia coli in water. Analyst 2018, 143, 4074-4082. [CrossRef]

135. Kapoor, V.; Gupta, I.; Pasha, A.B.M.T.; Phan, D. Real-Time Quantitative PCR Measurements of Fecal Indicator Bacteria and Human-Associated Source Tracking Markers in a Texas River following Hurricane Harvey. Environ. Sci. Technol. Lett. 2018, 5, 322-328. [CrossRef]

136. Bej, A.K.; Steffan, R.J.; DiCesare, J.; Haff, L.; Atlas, R.M. Detection of coliform bacteria in water by polymerase chain reaction and gene probes. Appl. Environ. Microbiol. 1990, 56, 307-314. [CrossRef]

137. Maraccini, P.A.; Mattioli, M.C.M.; Sassoubre, L.M.; Cao, Y.; Griffith, J.F.; Ervin, J.S.; Van De Werfhorst, L.C.; Boehm, A.B. Solar Inactivation of Enterococci and Escherichia coli in Natural Waters: Effects of Water Absorbance and Depth. Environ. Sci. Technol. 2016, 50, 5068-5076. [CrossRef]

138. Thayagan, S. Rapid Detection of Escherichia coli in Field Based Potable Water Applications. Master's Thesis, Virginia Polytechnic Institute and State University, Blacksburg, VA, USA, 2018.

139. Khamis, K.; Bradley, C.; Hannah, D.M. Understanding dissolved organic matter dynamics in urban catchments: Insights from in situ fluorescence sensor technology. Wiley Interdiscip. Rev. Water 2018, 5, e1259. [CrossRef]

140. Kissinger, J.; Wilson, D. Portable fluorescence lifetime detection for chlorophyll analysis in marine environments. IEEE Sens. J. 2011, 11, 288-295. [CrossRef]

141. Knapik, H.G.; Fernandes, C.V.S.; de Azevedo, J.C.R.; do Amaral Porto, M.F. Applicability of Fluorescence and Absorbance Spectroscopy to Estimate Organic Pollution in Rivers. Environ. Eng. Sci. 2014, 31, 653-663. [CrossRef]

142. Zhu, G.; Yin, J.; Zhang, P.; Wang, X.; Fan, G.; Hua, B.; Ren, B.; Zheng, H.; Deng, B. DOM removal by flocculation process: Fluorescence excitation-emission matrix spectroscopy (EEMs) characterization. Desalination 2014, 346, 38-45. [CrossRef]

143. Homola, J. Surface plasmon resonance sensors for detection of chemical and biological species. Chem. Rev. 2008, 108, 462-493. [CrossRef]

144. Hesari, N.; Alum, A.; Elzein, M.; Abbaszadegan, M. A biosensor platform for rapid detection of E. coli in drinking water. Enzyme Microb. Technol. 2016, 83, 22-28. [CrossRef]

145. Hesari, N.; Yilmazçoban, N.K.; Elzein, M.; Alum, A.; Abbaszadegan, M. A strategy to establish a quality assurance/quality control plan for the application of biosensors for the detection of E. coli in water. Biosensors 2017, 7, 3. [CrossRef]

146. Wutor, V.C.; Togo, C.A.; Pletschke, B.I. Comparison of the direct enzyme assay method with the membrane filtration technique in the quantification and monitoring of microbial indicator organisms-Seasonal variations in the activities of coliforms and E. coli, temperature and pH. Water SA 2007, 33, 107-110. [CrossRef] 
147. Baudart, J.; Lebaron, P. Rapid detection of Escherichia coli in waters using fluorescent in situ hybridization, direct viable counting and solid phase cytometry. J. Appl. Microbiol. 2010, 109, 1253-1264. [CrossRef] [PubMed]

148. Wutor, V.C.; Togo, C.A.; Pletschke, B.I. Suitability of total coliform $\beta$-D-galactosidase activity and CFU counts in monitoring faecal contamination of environmental water samples. Water $S A$ 2009, 35, 85-88. [CrossRef]

149. Kim, T.; Han, J.-I. Fast detection and quantification of Escherichia coli using the base principle of the microbial fuel cell. J. Environ. Manag. 2013, 130, 267-275. [CrossRef] [PubMed]

150. Briciu-Burghina, C.; Heery, B.; Regan, F. Continuous fluorometric method for measuring $\beta$-glucuronidase activity: Comparative analysis of three fluorogenic substrates. Analyst 2015, 140, 5953-5964. [CrossRef] [PubMed]

(C) 2020 by the authors. Licensee MDPI, Basel, Switzerland. This article is an open access article distributed under the terms and conditions of the Creative Commons Attribution (CC BY) license (http://creativecommons.org/licenses/by/4.0/). 